\title{
The Relevance of Targeting Treatment to Small Airways in Asthma and COPD
}

\author{
Pierachille Santus, Dejan Radovanovic, Matteo Pecchiari, Matteo Ferrando, Francesco Tursi, \\ Vincenzo Patella, and Fulvio Braido
}

\author{
Introduction \\ Pathophysiology of Small Airways in Asthma and COPD \\ Defining Small Airways \\ The Silent Zone \\ Pathobiology of Small Airways in COPD \\ Pathobiology of Small Airways in Asthma \\ Small Airways and Severe Asthma \\ Small Airways Assessment \\ Plethysmography \\ Forced Oscillation Technique and Impulse Oscillometry \\ Peripheral Exhaled NO \\ Imaging \\ Cytology of Induced Sputum \\ Treating Small Airways in Asthma and COPD \\ Delivery Systems Targeting Small Airways \\ Pharmacologic Targeting of Small Airways in Asthma \\ Pharmacologic Targeting of Small Airways in COPD \\ Clinical Implications and Future Developments \\ Summary
}

COPD and asthma have different risk factors and pathogenesis, but they share a pathophysiologic hallmark characterized by small airways disease. Although difficult to explore and measure, modifications of distal airways' pathophysiology and biology represent an early sign of obstructive disease and should be researched and assessed in everyday clinical practice. In the last 15 years, computed microtomography scans have shed light on the anatomy and physiology of the so-called silent zone, and research devoted to investigate the effect of inhaled treatments on small airway pathophysiology has been increasing. This narrative review offers a historical summary of researchers and landmark studies that reported, defined, and advanced the research on small airways. We then discuss the latest findings on the role and characteristics of the small airways' inflammatory and cellular structure, and we describe the assessment tools available to detect small airways dysfunction in COPD and asthma and the effect of bronchodilators and inhaled steroids on functional and biological biomarkers. Finally, we analyze the newest technological therapeutic advances aimed at small airways treatment in terms of inhalation devices and small particle size molecules. Key words: small airways; COPD; asthma; severe asthma; small particles; ventilation inhomogeneity; closing volume. [Respir Care 2020;65(9):1392-1412. (C) 2020 Daedalus Enterprises] 


\section{Introduction}

Asthma and COPD represent 2 of the most common noncommunicable diseases worldwide. Globally, asthma is the most prevalent chronic respiratory disease, with around 339 million people affected (http://globalasthmareport.org, Accessed February 24, 2019); COPD prevalence is continuously increasing, estimates being around 251 million cases in 2016 (https://www.who.int/respiratory/copd/burden/en, Accessed February 24, 2019). Despite advances in therapy and prevention, it is estimated that 1,000 people die each day from asthma ( $\sim 400,000$ each year); deaths from COPD are 8 times more common, and COPD is projected to be the third leading cause of death worldwide by 2030 (https://www.who.int/respiratory/copd/burden/en, Accessed February 24, 2019). Asthma and COPD both represent an unbearable social and economic burden on health care systems all over the world. Although these diseases differ regarding risk factors and natural history, they both present with alterations of the small airways. ${ }^{1-3}$ The importance of the peripheral airways in the pathophysiology and clinical manifestations of asthma and COPD make them the intuitive target for long-term pharmacologic approaches. ${ }^{4}$ However, the so-called silent zone of the lung has been always difficult to

Drs Santus and Radovanovic are affiliated with the Department of Biomedical and Clinical Sciences (DIBIC), Università degli Studi di Milano, Milan, Italy. Drs Santus and Radovanovic are affiliated with the Division of Respiratory Diseases, Ospedale L Sacco, ASST Fatebenefratelli-Sacco, Milan, Italy. Dr Pecchiari is affiliated with the Department of Clinical and Surgical Pathophysiology and Transplantation, Università degli Studi di Milano, Milan, Italy. Drs Ferrando and Braido are affiliated with the Department of Internal Medicine, Respiratory Diseases and Allergy Clinic, University of Genova, Azienda Policlinico IRCCs San Martino, Genova, Italy. Dr Tursi is affiliated with the Azienda Socio Sanitaria Territoriale di Lodi, Dipartimento Medico, USC Pneumologia, USS Servizio di Pneumologia, Ospedale di Codogno, Lodi, Italy. Dr Patella is affiliated with the Allergology and Clinical Immunology Unit, Department of Medical Sciences, Battipaglia Hospital, Salerno, Italy.

Dr Santus has disclosed relationships with Chiesi Farmaceutici, AirLiquide, Pfizer, Almirall, Astra Zeneca, Boehringer Ingelheim, Novartis, Menarini, Malesci/Guidotti, Mundipharma, and Zambon. Dr Radovanovic has disclosed relationships with Boehringer Ingelheim, Astra Zeneca, and Neopharmed Gentili. Dr Patella has disclosed relationships with Astra Zeneca, Menarini, and the Italian Drug Agency (AIFA). Dr Braido has disclosed relationships with AstraZeneca, Biofutura, Boehringer Ingelheim, Chiesi Farmaceutici, Dompè, GlaxoSmithKline, Lallemand Pharma, Malesci/Guidotti, Menarini Group, Mundipharma, Novartis, Teva, and Zambon. The remaining authors have disclosed no conflicts of interest.

Correspondence: Dejan Radovanovic MD, Department of Biomedical and Clinical Sciences, Università degli Studi di Milano, Division of Respiratory Diseases, Ospedale L. Sacco, ASST Fatebenefratelli-Sacco, Via G.B. Grassi 74, Milan, Italy, 20157. E-mail: dejan.radovanovic@asst-fbf-sacco.it.

DOI: $10.4187 /$ respcare.07237 access, and the lack of standardized and unanimously accepted methods of measurement has often left the assessment of the small airways to the experimental and investigational level, never becoming accessible to clinical practice. ${ }^{5,6}$ In the last 20 years, however, due to better, more reliable, and more standardized techniques, the study of small airways has gained renewed interest. Bronchodilators and inhaled steroids represent the treatment mainstay for COPD and asthma, respectively. Technological progress has allowed the development of new delivery systems and drug formulations designed to increase drug deposition and to improve therapeutic efficiency, effectiveness, and drug safety. ${ }^{7}$

This narrative review introduces the concept of small airways disease pathophysiology and biology, then summarizes the latest findings and advances in the assessment of small airways, and finally provides an overview of the pharmacology and mechanics behind molecule and delivery systems that are currently available for the treatment of asthma and COPD.

\section{Pathophysiology of Small Airways in Asthma and COPD}

\section{Defining Small Airways}

The section provides a brief description of the evolution of airway physiology that led to the current notion that the airways with a diameter $<2 \mathrm{~mm}$ offer very low resistance in normal lungs. A schematic representation of the main steps that led to the discovery of small airway pathophysiology is reported in Figure 1.

Since 1915, following the studies by Fritz Rohrer, it was thought that the main contribution to air-flow resistance within the respiratory system came from the small conducting airways. ${ }^{8}$ In fact, Rohrer, ${ }^{5}$ studying 1 excised undistended lung, noted that the cross-sectional area at every successive branching did not increase as he traced the trachea-bronchial tree, which supports the idea that there is a significant pressure drop along the bronchial generations, ie, an increase in resistance for every daughter branch almost twice that of the parent bronchial branch (Fig. 1). What Rohrer was missing in his aerodynamic calculations was that, in inflated lungs, total cross-sectional area of the conducting airways increased exponentially as the gasexchanging surface was approached, a piece of information added only in 1963 by Ewald R Weibel. ${ }^{9}$ In 1965, Malcolm Green ${ }^{10}$ calculated for the first time the airway resistance, unifying 2 paramount concepts into lung pathophysiology, ie, the Hagen-Poiseuille equation and the Weibel quantitative morphometric studies (Fig. 1) ${ }^{9}$ and demonstrating that the peripheral airways contributed to $<10 \%$ of total airway resistance, much less than what was estimated by Rohrer. ${ }^{5}$ The explanation for such a phenomenon was that the small 
1915

Rohrer

estimates airway resistance

in undistended lungs

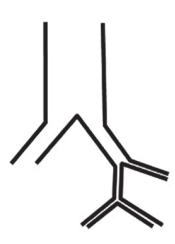

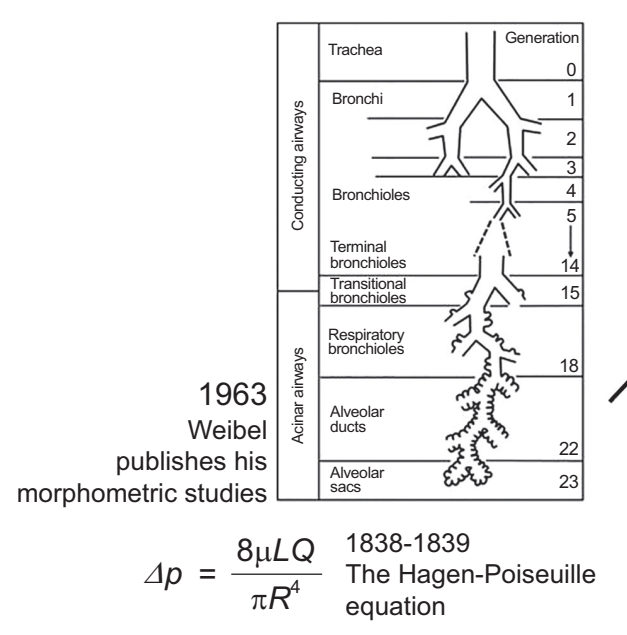
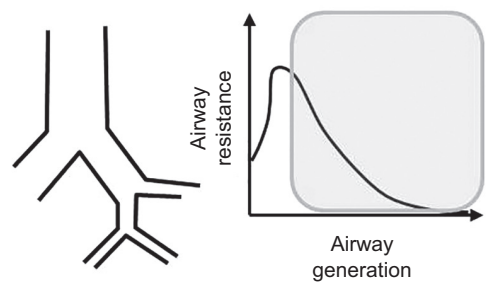

1965

Green demonstrates that peripheral airways contribute to $<10 \%$ of total airway resistancett

1968

Hogg, Macklem and Thurlbeck

introduce the term small airways, the major site of airflow obstruction in patients with emphysema

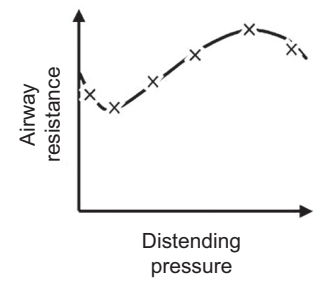

1967

Macklem and Mead

directly measure the resistance in airways $<2 \mathrm{~mm}$ with a retrograde catheter

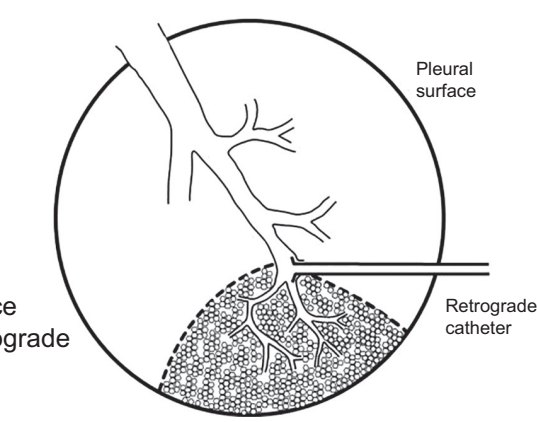

Fig. 1. Brief historical overview showing the milestones that lead to the discovery of the nature of airway resistance ${ }^{8}$ and to small airways mechanics. In 1915, Fritz Rohrer erroneously posited that the peripheral airways were the major site of airway resistance; integrating the lung morphometric studies performed by Weibel ${ }^{9}$ with the Hagen-Poiseuille equation, Green estimated that peripheral airways contribute to $<10 \%$ of total airway resistance. ${ }^{10}$ In 1967, Peter T Macklem and Jere Mead directly measured the resistance in airways $<2 \mathrm{~mm}$ in diameter, ${ }^{13}$ confirming the estimation made by Green. Soon after, Hogg, Macklem, and Thurlbeck reported that the small airways are the major site of airway resistance in patients with emphysema. The gray area in the airway generation-resistance diagrams represents airways $<2 \mathrm{~mm}$.

airways' cross-sectional area was much larger compared with conductive airways. In fact, starting from the fifth or sixth airway bronchial generation, the total airway crosssectional area increases exponentially due to a semi-dichotomous branching system and a greater cross-sectional area of the 2 daughter branches compared with their parent branch. $^{9,11}$ As a result of this anatomical structure, the closer the exchange surface, the shorter and more compacted the airways, allowing the high velocity and turbulent flow from the proximal airways to become laminar and independent of density in lung periphery. ${ }^{12}$

Soon after, directly measuring resistance in airways $<2$ $\mathrm{mm}$ by means of a retrograde catheter, Macklem and Mead ${ }^{13}$ confirmed Green's calculations and demonstrated how peripheral airways offered very low resistance in normal lungs (Fig. 1). One year later, the term small airways was introduced in a seminal paper by Hogg et $\mathrm{al}^{6}{ }^{6}$ which confirmed Macklem and Mead's experimental data in human lungs ${ }^{13}$ and reported that the small airways were the major site of air-flow obstruction and increased resistance in patients with emphysema (Fig. 1). ${ }^{6}$ Despite some discordance in the absolute measurement of small airway resistance,${ }^{14}$ all the evidence produced in the following decades experimentally confirmed that, in healthy subjects, airways $<2 \mathrm{~mm}$ in diameter carried a very low resistance, whereas resistance was very much increased in diseased lungs in patients with COPD. ${ }^{15}$ Hogg et $\mathrm{al}^{6}$ also noted that the increased resistance was caused by both narrowing and distortion of the airways, coupled with signs of chronic inflammation, fibrosis, and mucus plugging. Later experiments, however, indicated that obstruction of the small airways had very little effect on the mechanical properties of the lung because of the presence of collateral ventilation. ${ }^{15}$ By allowing lung regions beyond the obstructed ones to be ventilated, collateral ventilation affects the distribution of inspired gases and causes lung ventilation inhomogeneity, although this only minimally affects the mechanical properties of the lung. This was later supported by Hogg and 
colleagues ${ }^{16}$ by means of the single-breath nitrogen washout test (SBN2).

\section{The Silent Zone}

The redundancy of the lung obscures small airways disease, which becomes detectable with traditional lung function tests only when the lung periphery is consistently damaged. This section describes the pathophysiology of small airways and the need for effective pulmonary function tests.

The core investigations on pathophysiology and mechanics of small airways were predominantly conducted during the 1960s and 1970s, and the model that was most frequently adopted was chronic bronchitis and emphysema. At that time, it was clear that COPD was a condition related to cigarette smoking, with an insidious onset and an as-yet unclear epidemiology and natural history. Researchers were aware, however, that the earliest pathological changes in young tobacco smokers occurred in denuded epithelium and intramural inflammatory cells in the respiratory and membranous bronchioles. ${ }^{17}$ The latter, which occurred mainly in small airways, was known as peripheral airway disease. ${ }^{18}$ However, it was also clear that, before the damage became detectable with standard spirometric parameters such as $\mathrm{FEV}_{1}$ or $\mathrm{FVC}$, the number of diseased airways had to be huge..$^{5}$ Due to this particular feature, the small airways were referred as the silent zone of the lung. ${ }^{5,19}$ To identify early signs of disease, a series of new tests were developed. One of the earliest markers of precocious small airways damage was the identification of the frequency dependence of lung dynamic compliance in the case of small airway disease. Briefly, Woolcock and colleagues ${ }^{20}$ noted that, in contrast to healthy lungs, subjects with chronic bronchitis and asthma experienced a significant reduction of dynamic compliance during a wide range of breathing frequencies due to prolonged regional time constants, an observation that was not modified by the administration of bronchodilators. ${ }^{20}$ Together with the radioactive gas technique $^{21}$ and the SBN2 test, ${ }^{22}$ the dynamic compliance assessment was characterized by poor standardization and availability. ${ }^{18,20}$ Moreover, these tests were considered markers of early smoke exposure rather than having a significant clinical prognostic meaning. ${ }^{18}$

\section{Pathobiology of Small Airways in COPD}

The section deals with the immunology and inflammatory cells that characterize the airways of patients with COPD, with a peculiar focus to small airways. Inhalation of noxious particles, in western countries mainly represented by cigarette smoke, represents the most important risk factor for the development of COPD. ${ }^{23}$ In low-income countries, however, COPD can be also found in nonsmokers exposed to smoke from burning wood or biomass. ${ }^{24,25}$ The inflammation in COPD is localized predominantly to peripheral airways and lung parenchyma. ${ }^{26}$ Airways $<2 \mathrm{~mm}$ in diameter are more prone to undergo these pathological changes and thus to be occluded by mucus, inflammatory infiltrates, smooth muscle and mucus glands hypertrophy, and airway wall thickening, which involves the epithelium, the smooth muscle, and the adventitia. ${ }^{27}$

Compared with healthy individuals, the airway lumen of patients with COPD is rich in neutrophils and macrophages, and greater concentrations of macrophages, Tlymphocytes, and B-lymphocytes have been reported in the airway wall and parenchyma. ${ }^{23,27,28}$ The inflammatory response promoted by macrophages is upregulated by the nuclear transcription factor- $\kappa \mathrm{B}$ and by p38 mitogen-activated protein kinase. In turn, macrophages produce chemotactic agents for CD8+ and CD4+ lymphocytes. ${ }^{23,29}$ $\mathrm{CD} 8+$ cells induce apoptosis and necrosis of epithelial and endothelial cells, which likely contribute to the lung damage observed in patients with COPD. ${ }^{30}$ In COPD, activated neutrophils and lymphocytes infiltrate the small airways and are correlated with disease severity. ${ }^{31-33}$ Neutrophils contribute to alveolar destruction by producing myeloperoxidase, neutrophil elastase, matrix metalloproteinase- 8 , and matrix metalloproteinase- $9,{ }^{23}$ with the latter mediators also being responsible for increased mucus production. ${ }^{34}$ Inconsistent results have been published on the presence of eosinophils in the bronchoalveolar lavage of subjects with COPD. Higher eosinophil concentrations may be regulated by epithelial mediators such as interleukin-33 (IL-33) in response to epithelial cell injury. ${ }^{35}$

Upregulation of the histone deacetylase (HDAC) activity is one of the mechanisms by which corticosteroids inhibit inflammation. The neutrophil- and macrophage-driven reactive oxygen species released secondary to cigarette smoke exposure is responsible for the inactivation of HDAC-2. In fact, the activities of HDAC-2, $-3,-5$, and -8 have all been demonstrated to be reduced in COPD patients, suggesting a role for the inactivation of HDACs in steroid insensitivity in COPD. ${ }^{23,26,36}$ Isajevs and coworkers ${ }^{37}$ reported that cigarette smoke increased pro-inflammatory cytokines through the activation of nuclear transcription factor $-\kappa \mathrm{B}$ and by inhibiting HDAC-2. Nuclear transcription factor$\kappa \mathrm{B}$ p65 expression was greater in large airways, correlating with an increased number of macrophages, whereas the HDAC-2 expression was mainly decreased in small airways, suggesting its potential role in the development of bronchiolitis. ${ }^{37}$

\section{Pathobiology of Small Airways in Asthma}

The section deals with the immunology and inflammatory cells that characterize the airways of patients with asthma, with a particular focus on small airways. The role of the 
peripheral airways in asthma is increasingly recognized as a relevant target for asthma treatment. ${ }^{38,39}$ Previous research conducted on ex vivo lung specimens and transbronchial biopsies indicates that inflammatory and structural changes occur in both small airways and lung parenchyma of subjects with asthma. ${ }^{40-42}$ Thus the contribution of small airways to the pathobiology of asthma, combined with the presence of the relevant receptors in these airways, suggest that this site should not be neglected in the clinical monitoring of asthma or for the development of new treatments for the disease. ${ }^{43}$ Due to the anatomical site, procedural limitations, and the relatively poor availability of histological samples, the evaluation of the cellularity of small airways in asthma has always been difficult, all the more so if we consider that the majority of specimens are obtained during asthma exacerbations leading to a patient's death, which do not reflect the disease in a stable state.

Inflammatory changes of the proximal airways of subjects with asthma also occur in the distal airways. ${ }^{44}$ Small airways of patients with asthma are thickened and the airway wall is infiltrated by a variable distribution of eosinophils, T-lymphocytes, neutrophils, and macrophages. Moreover, small airways often present histological signs of obstruction secondary to mucus plugging and epithelial damage. ${ }^{45}$ An increased amount of activated eosinophils have been described in peripheral airways compared with large conductive airways in subjects with asthma, suggesting a significant inflammatory process localized in lung periphery. ${ }^{40} \mathrm{In}$ fact, in subjects who died from severe asthma, eosinophils and CD45+ leukocytes were found mainly in the outer wall of small airways. ${ }^{46}$ Accordingly, Hamid and colleagues ${ }^{40}$ reported a higher number of lymphocytes, eosinophils, and neutrophils associated with an increased mRNA expression of IL-4, IL-5, and eotaxin. This finding was confirmed with increased IL-4 and IL-5 mRNA-positive cells found in small airways in patients with mild and moderate asthma. ${ }^{47}$ These modifications may contribute to an uncoupling of the small airways from the surrounding lung parenchyma, promoting airway closure and collapse. ${ }^{48}$

\section{Small Airways and Severe Asthma}

The section focuses on the role of small airways in the pathophysiology and inflammatory patterns in fatal and severe asthma. Studies performed in subjects with asthma have confirmed that the inflammatory changes to the peripheral airways parallel the severity of the disease. In a study by Carroll et al, ${ }^{49}$ the increased expression of mast cell chymase in the outer area of the distal airways was significantly associated with impaired lung function in individuals with severe asthma. Compared to subjects with mild to moderate asthma, subjects with severe asthma exhibited an increased production of alveolar nitric oxide
(NO) but not bronchial NO, implying that a more intense degree of inflammation occurs in the periphery of the bronchial tree in the most severe forms of asthma ${ }^{50}$ In patients with severe or fatal asthma, there is increased thickness of the airway smooth muscle layer in the proximal and distal airways and increased smooth muscle cell size. ${ }^{51}$

In patients with severe asthma, the progressive loss of lung function is caused by structural alterations and remodeling of the proximal and distal airways. ${ }^{52}$ Specific abnormalities of the distal airways and lung parenchyma have also been described in nocturnal asthma, which occurs in $30-75 \%$ of the asthmatic population. ${ }^{53}$ In nocturnal asthma, but not in non-nocturnal asthma, a more pronounced inflammation was described in the peripheral airways rather than in the large central airways, with a significant increase in lymphocytes, macrophages, and eosinophils during the night. ${ }^{54}$ Autopsy studies have reported increased numbers of lymphocytes and eosinophils uniformly distributed throughout the large and small airways in lung tissue from individuals with fatal cases of asthma and from subjects with mild and severe asthma who died of other causes, compared to control subjects with no history of asthma. ${ }^{40,41}$

The percentage of eosinophils and macrophages was also significantly increased in the alveolar tissue and was related to a nocturnal reduction in lung function. The inflammatory response observed in the context of the alveolar tissue could explain the loss of airways-parenchyma coupling detected in individuals with nocturnal asthma. ${ }^{55}$ Reduced macrophage phagocytosis of bacteria has also been described in subjects with severe asthma. ${ }^{56}$

\section{Small Airways Assessment}

The section discusses the latest evidence in terms of small airway disease assessment and quantification with lung function tests and inflammatory markers, with a special focus on lung ventilation heterogeneity and closing volume, as well as the radiological evaluation of small airways and the development of new technologies in small airways imaging.

\section{Plethysmography}

Mid-Expiratory Flows. The mean forced expiratory flow (FEF) between $25 \%$ and $75 \%$ of $\mathrm{FVC}\left(\mathrm{FEF}_{25-75}\right)$ is one of the most popular indices of peripheral airways obstruction, resembling the concavity of the flow-volume curve. ${ }^{57}$ However, its use in clinical practice is limited by physiologic variability and measurement inconsistency. ${ }^{58}$ The repeatability of $\mathrm{FEF}_{25-75}$ is affected by its volume dependence and might also be evidence of air-flow inhomogeneity because it is changed by the presence of severe air-flow obstruction..$^{59}$ Its value as a predictor of peripheral obstruction has also been 


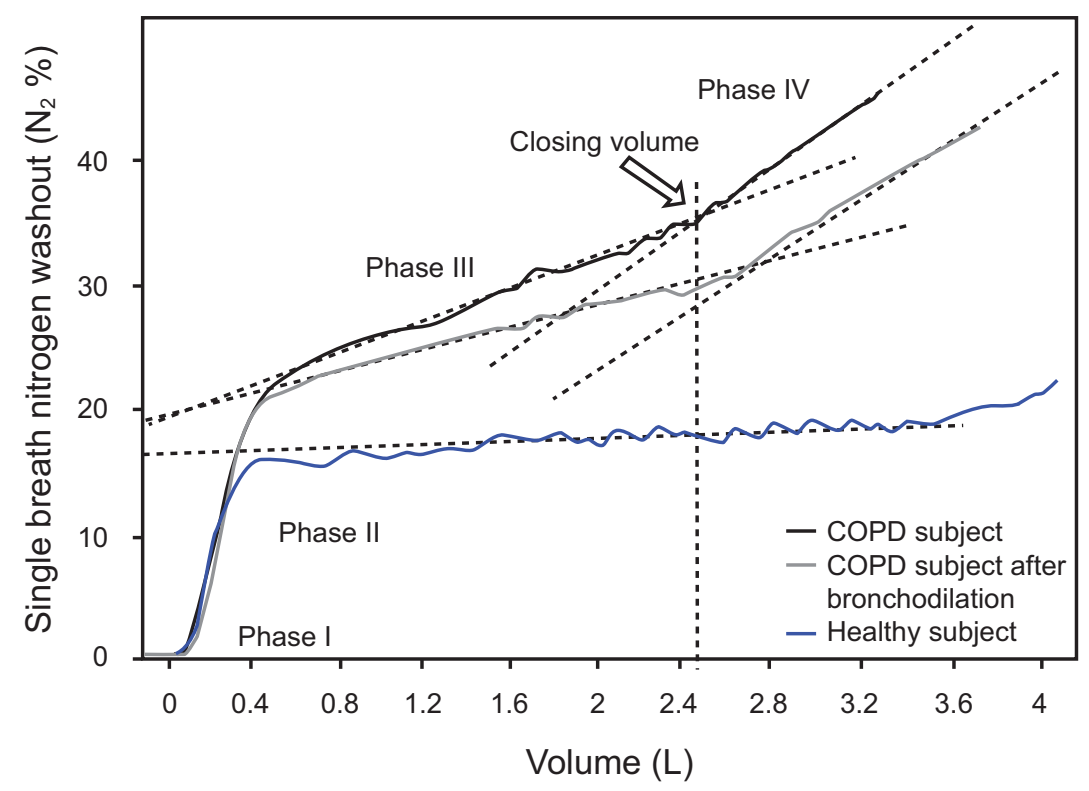

Fig. 2. Single-breath nitrogen washout test (SBN2) in a healthy young subject and a subject with severe COPD. The different phases that distinguish the SBN2 test are shown. The closing volume is the point at which the phase IV departs from the phase III plateau. The phase III slope is increased in subjects with COPD compared with normal subjects. After bronchodilator administration in the COPD subject, the phase III slope is reduced and the vital capacity is increased, with a consequent reduction in closing volume. The irregularities visible primarily on the tracing obtained in a healthy young subject represent the cardiac artifact.

questioned following findings from the Severe Asthma Research Program of the National Heart, Lung and Blood Institute, which reported a lack of correlation between $\mathrm{FEF}_{25-75}$ and other indices of air trapping. ${ }^{58}$

Lung Volume and Airway Resistance. Commonly employed spirometric tests, such as $\mathrm{FEV}_{1}$ and $\mathrm{FEV}_{1} / \mathrm{FVC}$, generally reflect large airways function. Vital capacity (VC), residual volume (RV), and FVC are, to some extent, correlated to the functional state of the peripheral airways. $\mathrm{VC}$ is reduced in patients with peripheral airways obstruction, and this reduction may occur before that of the $\mathrm{FEV}_{1} / \mathrm{VC}$ ratio. ${ }^{60} \mathrm{RV}$ is increased in patients with air trapping, a phenomenon that is secondary to alterations that occur mainly at the level of peripheral airways. ${ }^{38} \mathrm{FVC}$ is reduced at any level of airway obstruction, but it may be also a reflection of air trapping. ${ }^{38}$ In all normal lungs, the flow-volume curve depends on the density of the inhaled gas. ${ }^{61}$ Heliox is a mixture of $80 \%$ oxygen and $20 \%$ helium, and a decrease in pulmonary resistance is associated with an increase in maximum expiratory flow. ${ }^{61,62} \mathrm{In}$ patients with irreversible airway obstruction, breathing heliox can lead to an increase in resistance because this mixture has similar viscosity but a lower density compared with ambient air. ${ }^{63}$ Laminar flow resistance is viscosity-dependent, so in the presence of fully developed laminar flow there is a small increase in resistance. ${ }^{19}$ Despas and colleagues ${ }^{61}$ reported that adults with asthma fall into 2 groups: those who respond to heliox and those who do not respond. The greatest prevalence of nonresponders was represented by smokers with asthma who had recurrent infections with chronic cough and sputum production, ${ }^{64}$ implicating a possible role of small airways disease in the response to heliox. Recently, Sood and coworkers ${ }^{65}$ noted that methacholine-induced cough in subjects with otherwise preserved airway sensitivity was reflected by signs of small airways obstruction such as air trapping and hyperinflation. ${ }^{65}$

A spirometric pattern characterized by a decrease in VC and $\mathrm{FEV}_{1}$, an increase in RV and RV/total lung capacity, and a normal total lung capacity and $\mathrm{FEV}_{1} / \mathrm{FVC}$ was described by Stanescu and colleagues. ${ }^{66}$ This pattern has been suggested as an early sign of peripheral airways disease and has been observed in early emphysema stages, in elderly people and asymptomatic asthmatics. ${ }^{67,68}$ Although the RV represents a reliable and reproducible parameter, it is considered a poor mirror of small airways dysfunction and mainly reflects premature airway closure and air trapping. More recently, Santus and coworkers ${ }^{69}$ reported that dyspnea at rest in subjects with COPD was significantly related to specific airway resistance $\left(\mathrm{R}_{\mathrm{aw}}\right)$ rather than $\mathrm{FEV}_{1}$, and that acute changes in specific $\mathrm{R}_{\mathrm{aw}}$ induced by bronchodilators are significantly associated with improvements in dyspnea, whereas no correlation was observed with dynamic volumes. Indeed, the assessment and extent of bronchodilator responsiveness in terms of dynamic volumes is influenced by the slow or rapid inhalation maneuver preceding the evaluation of FVC. ${ }^{70}$ 


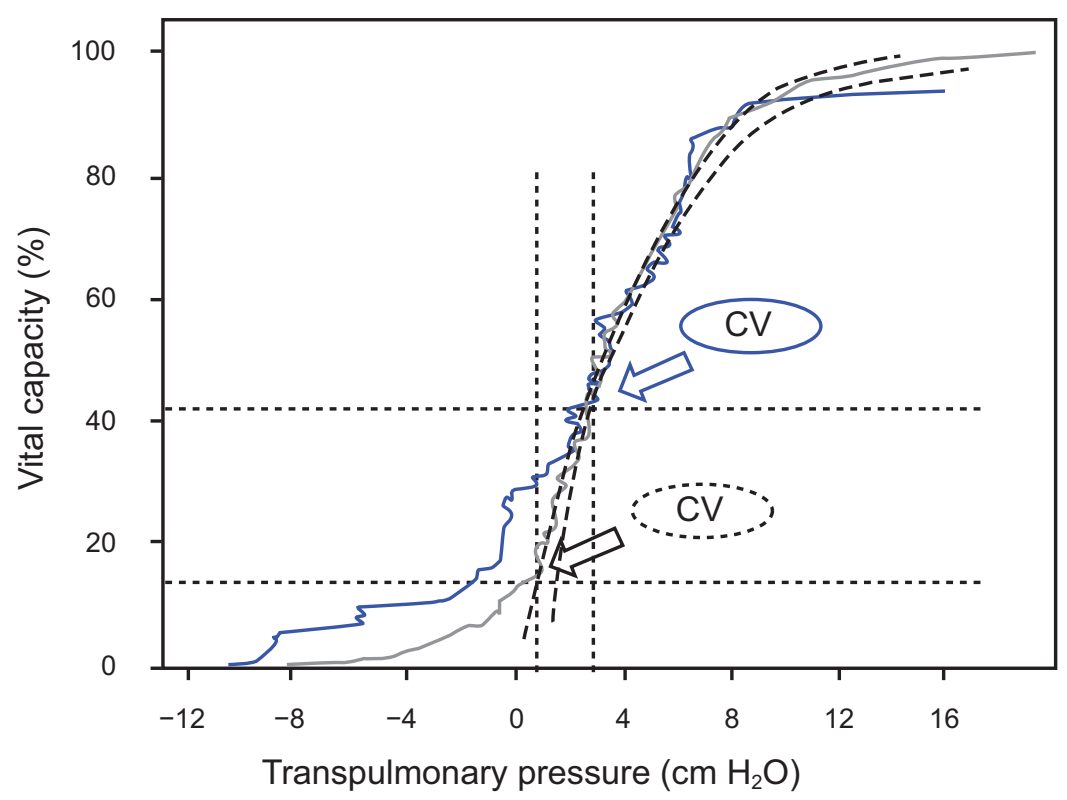

Fig. 3. Transpulmonary pressure-volume curves in a subject with severe COPD (blue line) and a healthy elderly subject (gray line). The tracings were obtained with the esophageal balloon technique. The CV is the point at which the curve departs from the exponential fit (dashed black exponential curve). Horizontal and vertical black dashed lines identify the transpulmonary pressure and the percentage of vital capacity for each CV. Note that, compared to the subject with COPD, the CV in the elderly subject happens at a lower percentage of vital capacity and at a lower traspulmonary pressure. $\mathrm{CV}=$ closing volume.

Lung Inhomogeneity and Closing Volume. Inhaled bronchodilators represent the treatment mainstay in COPD, and their functional target has always been the small airways. However, the evaluation of bronchodilator efficacy has often been limited to dynamic volume response, which poorly reflect small airway modifications. ${ }^{71}$ On the other hand, peripheral lung injury and poor distribution of ventilation can be assessed readily with the SBN2 test, reflected in a steeper slope of phase III and an increased closing volume. ${ }^{18}$

The SBN2 test is a noninvasive tool to assess small airways dysfunction and ventilation heterogeneity, and it has been used since the 1960s to detect early closure of peripheral airways. It is based on the detection of regional differences in ventilation distribution, represented by the phase III slope of the flow-volume curve following the washout test. Toward the end of expiration, an abrupt increase in $\mathrm{N}_{2}$ concentration is observed, which corresponds to the beginning of phase IV. This is due to the preferential emptying of the apex after the closure of airways at the base of the lung. The volume at which phase IV begins is termed closing volume $(\mathrm{CV})$, and it reflects small airways dysfunction. The CV identifies the point at which some regions of the lung stop contributing to lung deflation and trap air beyond functionally closed airways. ${ }^{18}$ An increased CV is responsible for 2 major abnormalities: poor distribution of ventilation with impaired gas exchange, and peripheral lung injury. ${ }^{18}$ Experiments in normal animals have shown that mechanical ventilation at low lung volume induces peripheral airway injury with concurrent increase in airway resistance. ${ }^{72,73}$ Further damage and a substantial inflammatory reaction occur in animal models when the collapse of small airways is promoted by increasing the surface tension, ${ }^{18}$ thus supporting the idea that cyclical opening and closing of the small airways during tidal breathing may also cause lung injury in humans. ${ }^{74}$ This should occur whenever $\mathrm{CV}$ exceeds the expiratory reserve volume, or when the closing capacity (ie, the sum of $\mathrm{CV}$ and RV) exceeds the functional residual capacity (Fig. 2). ${ }^{75}$ Despite being an easily performed and sensible technique, SBN2 is limited by poor reproducibility and predictability. ${ }^{76-77}$

The assessment of CV by means of the SBN2 test has been limited by the observation that, especially in patients with severe air-flow obstruction, phase IV is not present in a significant percentage of cases. ${ }^{78}$ Another proposed operational indicator of the onset of airway closure is represented by the inflection of the transpulmonary pressure-volume curve obtained during slow exhalation from total lung capacity (Fig. 3). ${ }^{79,80}$ Technical difficulties to obtain reliable transpulmonary pressure-volume curves and controversies concerning the criteria for the identification of the inflection point have limited the use of this indicator in humans. ${ }^{81,82}$ Recently, Pecchiari and coworkers ${ }^{75}$ simultaneously recorded the SBN2 test and the slow deflation transpulmonary pressure-volume curve in 40 healthy subjects and 43 subjects with COPD. The onset of phase IV identified the CV in SBN2 test, whereas in the transpulmonary pressure-volume curve the $\mathrm{CV}$ was identified by the deviation from the exponential fit and the inflection point 


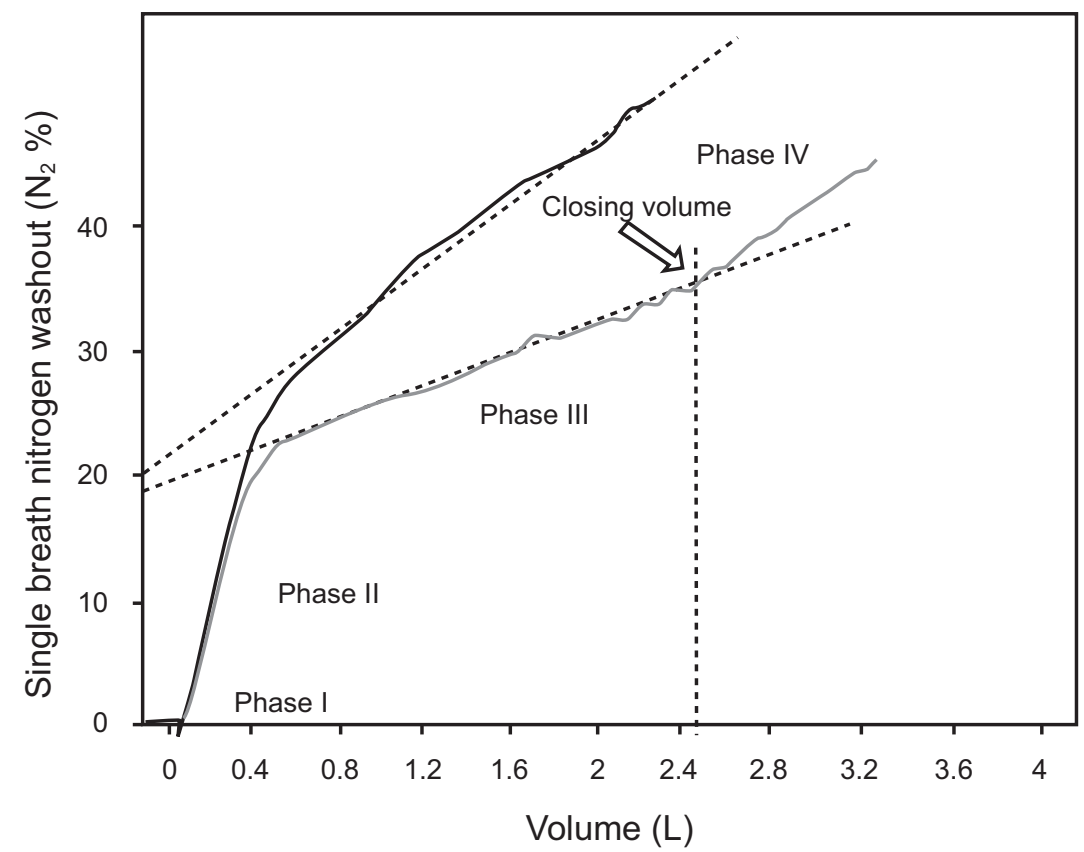

Fig. 4. Single-breath nitrogen test in a subject with severe COPD. The upper tracing (black line), despite a steep phase III slope, has no discernable phase IV. After bronchodilation (gray line), a discernable phase IV and thus a closing volume becomes visible. Note that both the phase III and the phase IV slopes are reduced after bronchodilator administration.

of the interpolating sigmoid function. The authors ${ }^{75}$ found that the CV evaluated with the SBN2 test always corresponded to the inflection point at the transpulmonary pressure-volume curve. However, in almost $50 \%$ of subjects with COPD, phase IV was not present during the SBN2 test, yet a clear inflection point at the transpulmonary pressure-volume curve was discernable. This evidence suggests that the absence of phase IV does not correspond to the absence of a $\mathrm{CV}$, probably reflecting a sign of increased ventilation heterogeneity (Fig. 4). ${ }^{83}$ The study also reported that almost $50 \%$ of subjects with COPD experience cyclic opening and closing of the airways during tidal breathing, a phenomenon that implies the presence of continuous stresses at the level of peripheral airways because such stress is a source of mechanically-driven inflammation and a plausible mechanism sustaining damage to the airways and disease progression..$^{84,85}$ Soon after, the same group demonstrated that both muscarinic antagonists and B-adrenergic agonists were similarly able to improve the heterogeneity of lung ventilation, positively affecting gas exchange and the extent of small airway closure in subjects with moderate to severe COPD, thus reducing the percentage who experienced cyclic opening and closure of the airways during tidal breathing (Fig. 5). ${ }^{86}$ Surprisingly, the administration of bronchodilators did not change the transpulmonary pressure at which the CV started, indicating that the effects were due to the reduced smooth muscle tone and improved airway compliance. The latter is the first-ever evidence of the potential effect of bronchodilator therapy as a key factor to reduce the risk of small airway damage in patients with COPD (Fig. 6) ${ }^{86}$ These hypotheses are complemented by the observations of Bhatt and colleagues, ${ }^{84}$ who reported how emphysema can mechanically influence surrounding areas of normal lung, thus increasing the risk of lung function decline. ${ }^{84}$

The multiple-breath nitrogen washout test measures functional residual capacity. Patients with high airway resistance take longer to clear the nitrogen, and the test can distinguish between obstructions in the large airways or the small airways. Dutrieue et $\mathrm{al}^{87}$ and Verbanck et al ${ }^{88}$ used the multiple-breath nitrogen washout test to derive 2 variables, the index of conductive ventilation heterogeneity and the index of acinar ventilation heterogeneity. In subjects with asthma, the clinical application of the multiple-breath nitrogen washout test includes evaluation of ventilation heterogeneity after an airway challenge and analysis of response differences to inhaled steroids when comparing nonextrafine and extrafine particles. ${ }^{89,90}$ The influence of aging on ventilation heterogeneity needs to be taken into consideration. In this scenario, Verbanck and colleagues ${ }^{91}$ recently reported that, with respect to clinical response, age has a small but consistent effect that needs to be factored in when using the multiplebreath nitrogen washout test indices for the detection of small airways abnormality in disease.

\section{Forced Oscillation Technique and Impulse Oscillometry}

The forced oscillation technique works by superimposing pressure oscillatory waves on the airway during tidal 

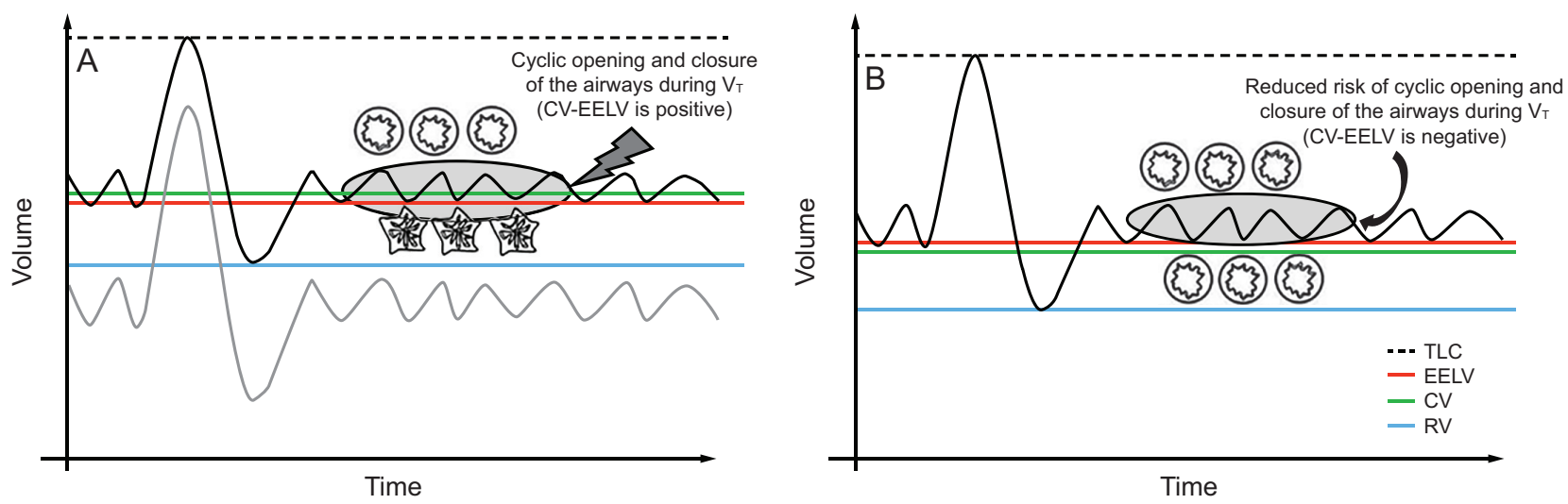

Fig. 5. A: Hypothetical volume-time tracings obtained in a healthy subject (gray line) and in a subject with severe COPD (black line). In the subject with severe COPD, the RV and the TLC are increased. Note that, during tidal breathing, patients with COPD can incur into cyclic opening and closure of the airways because the CV is greater than the EELV. B: After bronchodilation, due to the increase in vital capacity secondary to the decrease in functional residual capacity and $\mathrm{RV}$, the $\mathrm{CV}$ is reduced and is not within the $\mathrm{V}_{\mathrm{T}}$ anymore, allowing the airways to be patent during tidal breathing. $\mathrm{TLC}=$ total lung capacity; $\mathrm{RV}=$ residual volume; $\mathrm{EELV}=$ end-expiratory lung volume; $\mathrm{CV}=$ closing volume; $\mathrm{V}_{\mathrm{T}}=$ tidal volume.

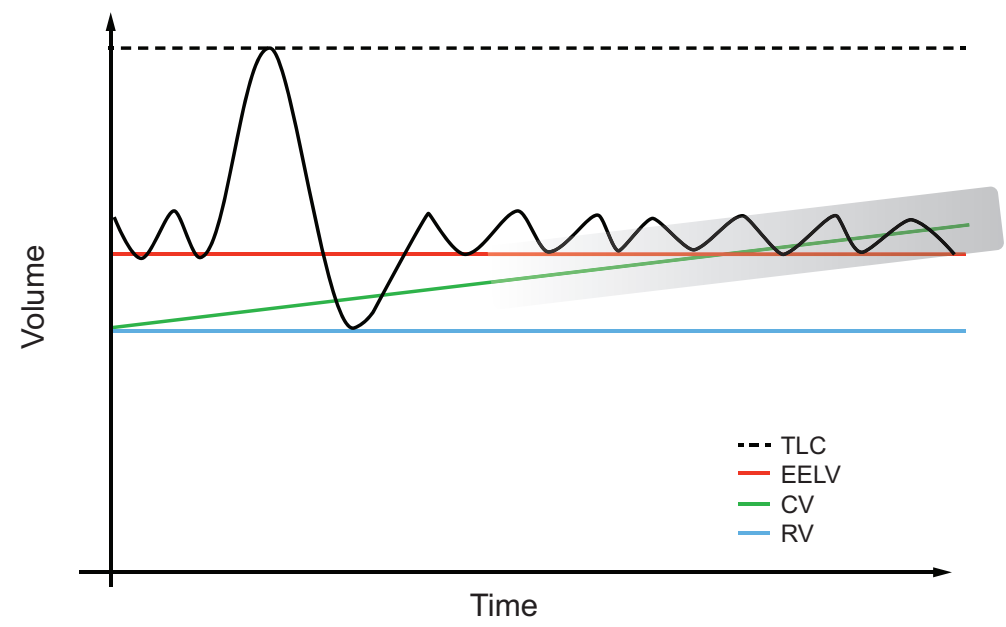

Fig. 6. A schematic view of the possible relationship between CV and other static lung volumes in patients with COPD. Patients with closing volume proximal to RV have a low chance to incur into tidal airway opening and closure, whereas patients for whom CV is within the resting tidal volume can easily incur into cyclic opening and closure of the airways. The gray area represents a hypothetical zone of heightened risk of such a phenomenon (ZRACO = zone at risk of airway cyclic opening and closure). CV = closing volume; RV = residual volume; TLC = total lung capacity; EELV = end-expiratory lung volume.

breathing. The forced oscillation technique was first described by DuBois ${ }^{92}$ in 1956 as a method to characterize respiratory impedance. Both the forced oscillation technique and impulse oscillometry are easy to perform and require minimal patient cooperation..$^{93}$ Impulse oscillometry operates by delivering a continuous spectrum of frequencies, favoring the characterization of lung mechanics, ${ }^{94}$ both in adults and in preschool children with asthma. ${ }^{93,95}$ This method can reflect regional lung inhomogeneity and therefore represents a useful tool during bronchoprovocation challenges. Takeda and coworkers ${ }^{96}$ reported a strong correlation between impulse oscillometry parameters and clinical symptoms and asthma control in subjects with asthma. Impulse oscillometry allows a separate assessment of the peripheral and proximal airways, and it appears to be a sensitive screening tool for the early detection of airway obstruction. ${ }^{97}$ Oppenheimer and colleagues ${ }^{98}$ proposed that impulse oscillometry can be used as a noninvasive tool for assessment of distal airway function when spirometry is normal. More recently, the Assessment of Small Airways Involvement in Asthma study, ${ }^{99}$ a multinational prospective cohort study, explored the effects of small airway dysfunction in subjects with asthma. Small airway dysfunction was noted across all asthma severity stages; more importantly, however, subjects with milder asthma had an index of acinar ventilation heterogeneity within normal values, whereas impulse oscillometry parameters (ie, the fall in resistance from $5 \mathrm{~Hz}$ to $20 \mathrm{~Hz}$ [R5-R20]) and spirometric variables 


\section{Small Airways in Obstructive Disease}

were directly correlated with more severe involvement of the small airways. ${ }^{99}$

\section{Peripheral Exhaled NO}

The fraction of exhaled $\mathrm{NO}\left(\mathrm{F}_{\mathrm{ENO}}\right)$ is a reliable marker of airway eosinophilia, and it is measured in clinical practice and used in the follow-up of patients with asthma. In both asthma and COPD, $\mathrm{F}_{\mathrm{ENO}}$ levels are influenced by airway bronchoconstriction. ${ }^{100} \mathrm{~F}_{\mathrm{ENO}}$ and alveolar NO can be elevated in patients with COPD, independent of smoking status and disease severity, ${ }^{101,102}$ and levels $\geq 20$ parts per billion have been associated with a higher risk of exacerbation. ${ }^{103}$

More recently, Santus and coworkers ${ }^{104}$ reported that peripheral $\mathrm{NO}$, in particular the alveolar fraction of $\mathrm{F}_{\mathrm{ENO}}$, is associated with the amount of air trapping and diffusion capacity derangement in subjects with COPD. Moreover, after administration of long-acting $\beta_{2}$-agonists in acute conditions, $F_{\mathrm{ENO}}$ was reduced and the decrease in peripheral $\mathrm{NO}$ was correlated with the degree of improvement of lung ventilation inhomogeneity and air trapping. ${ }^{104}$ These data may indicate that NO in patients with COPD may reflect the amount of mechanical stress and strain-induced production of inflammatory mediators such as NO, sustaining the hypothesis that peripheral airway injury is one of the major determinants of COPD pathogenesis and its role in the disease's natural history. ${ }^{18}$ Although $\mathrm{F}_{\mathrm{ENO}}$ or alveolar NO evaluation seem to be potentially useful tools for COPD management, more data are needed to support their routine clinical use.

\section{Imaging}

Computed tomography (CT) has emerged as a useful tool to assess peripheral airways disease noninvasively in patients with asthma. The cardinal CT sign of peripheral airways disease in asthma is the presence of pulmonary decreased attenuation areas, which are more consistent on expiratory CT scans. ${ }^{105-107}$ Decreased attenuation areas reflect air trapping, which may be either secondary to transient small airway obstruction or spasm or may be caused by fixed peripheral remodeling. ${ }^{108,109}$

Two different systems are currently used to quantify air trapping on CT: the visual score and the densitometric analysis. The former is limited by the subjective approach that causes sometimes significant interobserver variability; thus the densitometric analysis has been the technique of choice in recent scientific investigations. Specifically, either mean lung density or $850 \mathrm{HU}$ cut-off CT density has been used to quantify air trapping in subjects with asthma. ${ }^{110,111}$

Quantification of air trapping in expiratory CTs may provide additional information on the effects of inhaled therapy targeted to small airways disease, dysfunction which may not be readily revealed with pathophysiological testing. ${ }^{109,112}$ The latter technique has been used to compare the relative efficacy of 2 different inhaled medications on small airway hyper-reactivity; small-size inhaled particles prompted a significant improvement in air trapping compared with traditional-size particles. ${ }^{109,111}$

Air-trapping quantification has also been used to define asthmatic phenotypes. A recent investigation by Busacker and colleagues ${ }^{111}$ reported that quantitative $\mathrm{CT}$ scan identified subjects with a high risk of severe disease. Subjects with air trapping above the median were significantly more likely to have a history of asthma-related hospitalizations, ICU visits, or mechanical ventilation. ${ }^{111} \mathrm{CT}$ imaging of pulmonary ventilation patterns in patients with asthma has evolved over the last decade with the introduction of more sophisticated techniques. The direct assessment of peripheral remodeling with CT measurements is still limited due to the difficulty to obtain accurate measures of the distal airways. Computer-assisted 3-dimensional analysis of the airway tree structure is currently advancing our knowledge on the anatomy and pathology of small airway disease. With this technique, researchers have reported that airway wall measurements of the distal airways have the strongest correlation with air-flow obstruction parameters in subjects with asthma. ${ }^{113}$

The spatial resolution of currently available high-resolution CT does not allow for an accurate assessment of small airways in patients with either asthma or COPD. Recent developments carried out by Tanabe and co-workers ${ }^{114}$ tested the possibility of using ultra-high-resolution $\mathrm{CT}$ to measure airway walls of bronchioles down to $2 \mathrm{~mm}$ in diameter with a significant reduction of the error rate compared to traditional high-resolution CT algorithms.

Although current evidence indicates that small airway obstruction could be routinely assessed with CT, this technique does have some limitations, including a lack of standardization of technical parameters for the CT scanner, a lack of consensus on the best index for small airways disease assessment, and exposure of subjects to ionizing radiation. Indeed, the regular assessment of small airway disease via $\mathrm{CT}$ imaging is still not part of routine clinical practice for young asthmatic patients.

To date, magnetic resonance imaging (MRI) of the lung has been cumbersome for two primary reasons: the density of lung parenchyma, which returns a weak magnetic resonance signal, and the many air-tissue interfaces, which introduce magnetic susceptibility effects and cause a rapid decay of the magnetic resonance signal in the lung. ${ }^{115}$ The development of new contrast agents such as hyperpolarized helium-3 $\left({ }^{3} \mathrm{He}\right)$ and xenon-19 $\left({ }^{19} \mathrm{Xe}\right)$ have allowed a much higher spatial and temporal resolution of MRI scans (eg, hyperpolarized gas lung MRI ventilation imaging). Helium is an inert gas that does not diffuse into pulmonary circulation, thus allowing the assessment of ventilation defects and heterogeneity, whereas xenon diffuses more rapidly to 


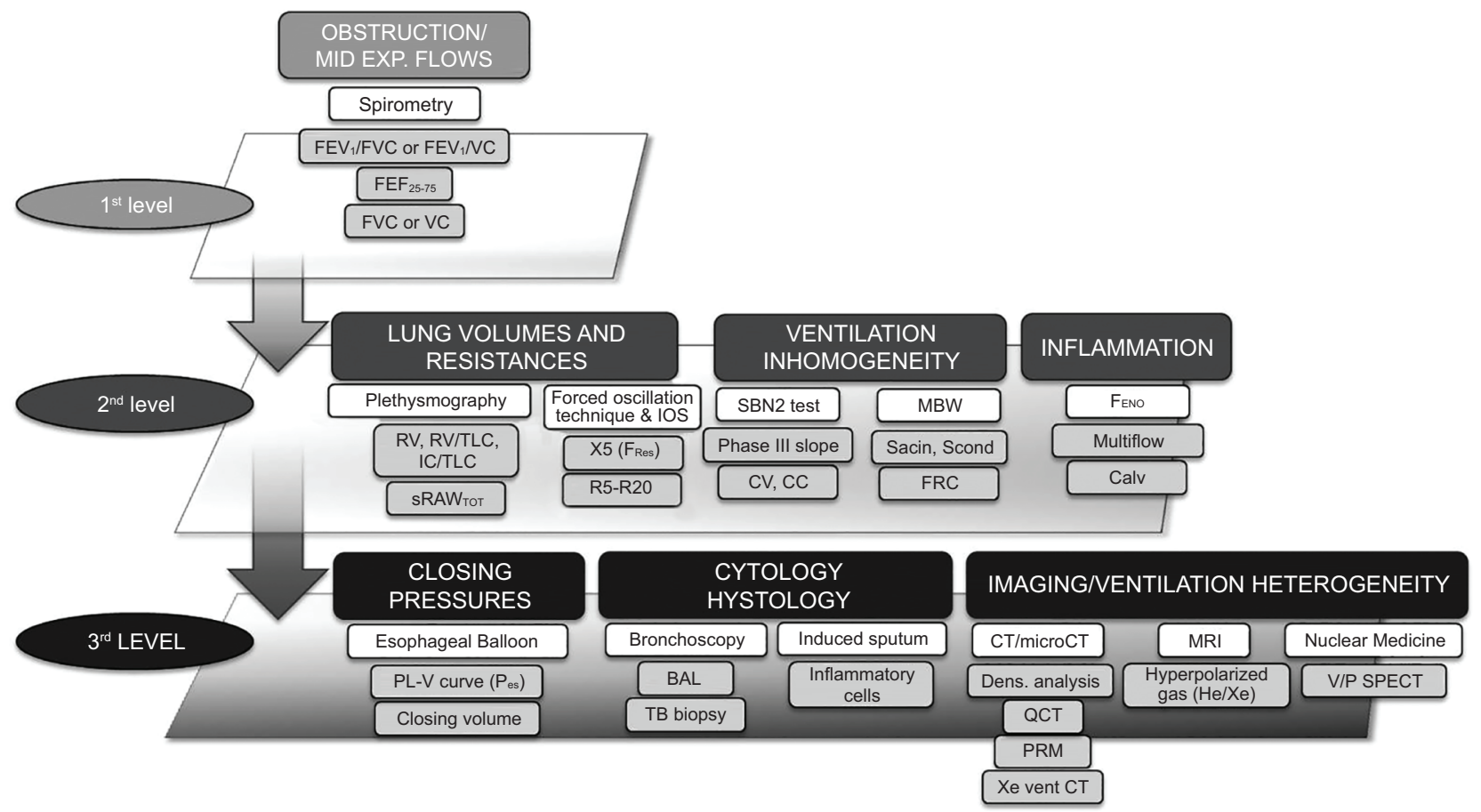

Fig. 7. Available noninvasive and invasive assessment tools for small airway assessment. Diagnostic tests are ordered based on complexity and availability from the simplest (upper level) to the most complex (lower level). $\mathrm{FVC}=$ forced vital capacity; $\mathrm{VC}=$ vital capacity; $\mathrm{RV}=$ residual capacity; IC = inspiratory capacity; sRawtot = total specific airway resistance; IOS = impulse oscillometry; SBN2 = single-breath nitrogren washout test; $\mathrm{CV}=$ closing volume; $\mathrm{CC}=$ closing capacity; $\mathrm{MBW}=$ multiple breath washout test; $\mathrm{FRC}=$ functional residual capacity; $\mathrm{F}_{\mathrm{ENO}}=$ fractional exhaled nitric oxide; Calv = alveolar nitric oxide concentration; $\mathrm{PL}-\mathrm{V}=$ transpulmonary pressure-volume curve; $\mathrm{BAL}=$ bronchoalveolar lavage; $\mathrm{TB}=$ transbronchial; $\mathrm{CT}=$ computed tomography; $\mathrm{QCT}=$ quantitative computerized tomography; $\mathrm{PRM}=$ parametric response mapping; Xe vent $=$ Xenon ventilation; $\mathrm{MRI}=$ magnetic resonance imaging; V/P SPECT $=$ ventilation-perfusion single-photon emission CT.

lung parenchyma and further in the capillary bed, allowing the assessment of both the gas phase and the dissolved phase for the simultaneous assessment of ventilation and perfusion. This technique has been used successfully in subjects with asthma to evaluate regional ventilation defects as well as air-flow obstruction and its reversibility after methacholine challenge after exposure to bronchodilators. ${ }^{116-118}$ Hyperpolarized ${ }^{3} \mathrm{He}$-diffusion MRI at multiple diffusion timescales and quantitative CT scan densitometry was compared to the multiple-breath nitrogen washout test by Gonem and co-workers ${ }^{119}$ to assess the acinar airway involvement in subjects with asthma. Gonem et $\mathrm{al}^{119}$ found that an increased index of acinar ventilation heterogeneity was associated with worse asthma severity, worse CT expiratory air-trapping indexes, and with the apparent diffusion coefficient of ${ }^{3} \mathrm{He}$ at $1 \mathrm{~s}$, a sign associated with alterations in long-range diffusion within the acinar airways. ${ }^{119}$ The objective of future research should be to integrate CT and MRI acquisitions with physiological measures of small airway dysfunction to provide both anatomo-radiological measures of peripheral airways and dynamic regional ventilation-perfusion defects.

According to recent evidence from pathoradiological studies, compared with control smokers, the number of terminal bronchioles in subjects with mild and moderate
COPD was decreased by $40 \%$ and $43 \%$, respectively, and the number of transitional bronchioles decreased by $56 \%$ and 59\%, respectively. ${ }^{120}$ Moreover, subjects with mild COPD and a preserved $\mathrm{FEV}_{1}$, compared with at-risk smokers, exhibited a $19 \%$ reduction in total airway count measured with CT scan (ie, the total airway count represents the major determinant for disease progression). ${ }^{85} \mathrm{~A}$ recent study from Vasilescu and co-workers ${ }^{121}$ offered for the first-ever evidence that the analysis of functional small airways disease obtained by means of parametric response mapping (PRM) on subjects with severe COPD is correlated with loss of terminal bronchioles, luminal narrowing, and obstruction of ex-vivo eclipsed lungs analyzed with micro-CT. The latter is one of the first examples of a radiomorphological marker able to identify small airways damage in patients with COPD. ${ }^{121}$ Indirect evidence that may support the importance of the progressive loss of treatable airways is reported in a post hoc analysis of the 4-y Understanding Potential Long-Term Impacts on Function with Tiotropium (UPLIFT) trial, which reported a progressive reduction in the extent of the acute bronchodilator response, a reduction that was increasingly pronounced in subjects with severe to very severe COPD. ${ }^{122}$ The decline in lung function was generally larger in subjects with severe to very severe than with mild to moderate air-flow 
obstruction, in older subjects ( $\geq 65 \mathrm{y}$ ), and in former rather than current smokers. ${ }^{123}$

In a study of small airway pathology performed on lungs from subjects with COPD, multidetector-row CT revealed a decreased number of airways that were $2-2.5 \mathrm{~mm}$ in diameter and the loss of lumen starting from fifth-generation airways; accordingly, the assessment with micro-CT revealed decreases in the number of terminal bronchioles and the lumen, wall volumes, and alveolar attachments of preterminal bronchioles (TB-1) and pre-preterminal bronchioles (TB-2). ${ }^{124}$ Micro-CT and histology also noted increased B cell infiltration of TB-1 and TB-2 walls, which correlated with a decreased number of alveolar attachments. These findings suggest that changes to the small airway related to disease extends from $2-\mathrm{mm}$ diameter airways to the terminal bronchioles, and that a B cell-mediated immune response may lead to the loss of alveolar attachments. ${ }^{125}$

In the last decade, ventilation-perfusion single-photonemission CT (V/P SPECT) has been recognized as a powerful tool to assess small airway dysfunction and early disease and to evaluate the presence of ventilation defects and comorbidities in patients with COPD. ${ }^{126-128}$ Airway obstruction, previously representing a limitation to nuclear imaging studies with hydrosoluble aerosols in patients with COPD, no longer represents an issue since the introduction of ultrafine aerosols such as Technegas, thus allowing the expansion of V/P SPECT application, which exhibited a higher sensitivity than chest $\mathrm{CT}$ and $\mathrm{FEV}_{1}$ in detecting early airway changes. ${ }^{128}$ In fact, Technegas penetration depends on small airway function, and bronchial deposition increases in small airway disease, thus allowing detection of airway obstruction earlier with Technegas ventilation image than with spirometry. ${ }^{129}$ Recently, Bajc and colleagues ${ }^{127}$ reported the possibility of using this technique to distinguish between healthy subjects and those with COPD, not only to grade disease severity but also to add important information on concomitant comorbidities in subjects with COPD, such as pulmonary embolism and heart failure with vascular or ventilation defects. Although promising, the technique requires standardization and refinement in terms of spatial resolution before it can be used to provide clinically useful data on small airway dysfunction and early disease in at-risk patients with normal lung function tests.

\section{Cytology of Induced Sputum}

Sputum induction after inhalation of hypertonic saline is a noninvasive technique that is valid for studying inflammatory cells in central airways. Modified protocols have been proposed to evaluate whether this method can also assess inflammation in small airways. In particular, it has been suggested that sequential inductions, performed after short intervals of time (ie, 20-30 min), may provide useful information on distal airway inflammation. ${ }^{130-132}$ However, this procedure may be associated with issues regarding reproducibility and standardization, and no studies have been performed to directly compare the inflammatory profile in sputum with small airways assessment through transbronchial biopsies. A schematic representation of the currently available assessment tools for small airways in asthma and COPD are reported in Figure 7.

\section{Treating Small Airways in Asthma and COPD}

This section summarizes the rationale for the development of devices and drug formulations that target the small airways and describes the physics behind the concept of small-particle delivery. This section also presents the latest bench and clinical evidence in the treatment of small airways in subjects with asthma or COPD.

\section{Delivery Systems Targeting Small Airways}

Small airway inflammation and dysfunction characterize specific clinical asthma phenotypes, such as nocturnal asthma, exercise-induced asthma, and allergic asthma. ${ }^{7}$ The transversal involvement of distal airways in different obstructive diseases such as asthma and COPD have justified research efforts to create pharmacologic treatments and technologies that can reach and target the peripheral airways.

Most inhaled therapies, however, do not sufficiently reach the small airways. ${ }^{133-135}$ Although the drug particle size pattern may vary markedly between inhalers, conventional pressurized metered dose inhalers (pMDIs) and most dry powder inhalers (DPIs) emit drug particles that are too large to effectively target the small airways. In fact, a high proportion of the drug deposits in the oropharynx, causing local and systemic effects through gastrointestinal absorption. ${ }^{136}$

Particle size is a critical factor determining the therapeutic efficacy of inhaled drugs. The mass median aerodynamic diameter (MMAD) is used to measure the heterogeneity of particles in an emitted dose. MMAD predicts the deposition and distribution of particles in the bronchial tree. Using radiolabeled salbutamol, Usmani and colleagues ${ }^{137}$ noted an inverse relationship between particle size and lung deposition. Lower MMAD reduces oral deposition, thereby attenuating the consequences of an incorrect inhalation technique. However, the optimal particle size for an inhaled drug to effectively reach and deposit in the small airways has not clearly been defined, as reflected by the different terms and sizes: sub-micron particles $(<1 \mu \mathrm{m})$; ultrafine particles $(1.1 \mu \mathrm{m})$, and extrafine particles $(1.5$ $\mu \mathrm{m}) .{ }^{138-140}$ Small particles are defined those with a MMAD $<2 \mu \mathrm{m}$, and inhaled formulations with MMAD $<2 \mu \mathrm{m}$ have been termed extrafine. ${ }^{139}$ 
The proportion of particles within the aerosol that are $<$ $5 \mu \mathrm{m}$ is often referred to as the fine-particle fraction, or the fine particle dose if expressed in absolute mass of drug. ${ }^{138}$ Both the particle size and the fine-particle fraction of an aerosol play a significant role for the deposition of an inhaled drug and its relative distribution within the large and small airways. ${ }^{7}$ The geometric standard deviation (GSD) is defined as the ratio of the median diameter to the diameter at $\pm 1 \mathrm{SD}$ from the median diameter, and it measures the dispersion of the particle diameter. ${ }^{141}$ If the particle size varies over a wide range (ie, GSD $>1.2 \mu \mathrm{m}$ ), the aerosol is described as having a polydisperse particle distribution; if the particles are of similar size (ie, GSD $<1.2 \mu \mathrm{m}$ ), the aerosol particle distribution is described as monodisperse. ${ }^{141}$ It has been reported in lung deposition studies that small-particle aerosols achieve better pulmonary deposition as well as effective penetration into the peripheral lung. Importantly, small-particle aerosols are not exhaled to any significantly greater level compared to large-particle aerosols when assessed using in vivo lung deposition studies. ${ }^{7}$

The available data suggest that the more distal deposition of small-particle formulations of inhaled corticosteroids (ICS) is safe in patients with asthma, and, for some drugs, distal deposition may even result in a reduced effect on the hypothalamic-pituitary-adrenal axis, most probably through less oropharyngeal deposition and hence decreased gastrointestinal bioavailability. ${ }^{142-145}$

\section{Pharmacologic Targeting of Small Airways in Asthma}

Recent technological advances in device engineering and drug formulation have led to a new generation of inhalers emitting small-particle drug aerosol at slower velocities, with enhanced lung deposition and more effective aerosol penetration into peripheral lung. The novel devices include solution-based hydrofluoroalkane-propelled pMDIs delivering ICS aerosols (eg, beclomethasone dipropionate, ciclesonide, and flunisolide), long-acting $\beta$-adrenergic bronchodilators (LABA) (eg, formoterol), and an ICS/LABA fixed-dose combination (eg, beclomethasone dipropionate/formoterol). Furthermore, a new multi-dose DPI (NextHaler, Chiesi, Italy), which delivers a smallparticle ICS/LABA combination, and the novel Soft-Mist inhaler (Boehringer Ingelheim, Germany), which delivers small-particle aerosols of long-acting bronchodilators, have been developed recently. The extrafine fixed-dose ICS/LABA (beclomethasone dipropionate/formoterol, 100/6 $\mu \mathrm{g})$ is delivered using both a pMDI and a DPI. Extrafine beclomethasone dipropionate/formoterol achieves satisfactory central and peripheral lung deposition, leading to an increased potential for synergistic interaction and improved efficacy. ${ }^{146-148}$

Increased resistances and inflammation-driven structural changes of peripheral airways in patients with asthma are involved in the lack of symptom control and enhanced exposure to sudden attacks across all disease severity stages. ${ }^{149-151}$ The development of extrafine formulations and the ability to reach the distal airways more effectively prioritized the pharmacologic management of small airways in asthma to reduce the future risk of exacerbations and side effects as well as to achieve better symptom control. ${ }^{4}$

The significant increase in peripheral airway deposition of the inhaled drug with respect to the delivered dose provided by extrafine formulations allows for better equivalence ratios when compared with nonextrafine formulations, thus reducing drug exposure and potentially minimizing the efficacy/safety ratio with comparable clinical efficacy. ${ }^{145,152}$ Extrafine ICS formulations have been reported to be superior to nonextrafine ICS in improving functional and inflammatory parameters of small airways in subjects with asthma. ${ }^{89,109}$

Papi and coworkers ${ }^{153}$ reported that the extrafine beclomethasone dipropionate/formoterol DPI formulation, assessed in subjects with moderate to severe asthma, was not inferior to a budesonide/formoterol DPI formulation in improving lung function and disease control, and with a comparable safety profile. This was also demonstrated when extrafine beclomethasone dipropionate/formoterol DPI was compared with salmeterol/fluticasone. ${ }^{154}$ In the latter case, subjects treated with beclomethasone dipropionate/formoterol achieved more rapid bronchodilation, with a significant reduction in air-trapping indexes, which is an indirect sign of improvement of small airway parameters. ${ }^{154}$ Real-life studies have also noted that a higher proportion of subjects treated with the extrafine beclomethasone dipropionate/ formoterol pMDI achieved asthma control with a lower cumulative exposure to daily ICS dose compared with nonextrafine formulations ${ }^{155,156}$

More recently, Marth et a ${ }^{157}$ confirmed previous randomized reports showing significant improvements in asthma control in subjects treated with extrafine beclomethasone dipropionate/formoterol, independent of smoking status, disease duration, or the presence of air trapping. Subjects with and without indirect signs of air trapping experienced a mean FVC increase of 700 and $400 \mathrm{~mL}$, respectively, confirming the effects of the study treatment on small airways. ${ }^{157}$ Contoli and colleagues ${ }^{158}$ noted significant improvements in phase III slope and R5-R20 values in smokers but not in never-smokers treated with beclomethasone dipropionate/formoterol. Conversely, Cox and co-workers ${ }^{159}$ showed no difference in the adenosine provocation dose and peripheral airway resistance when comparing an extrafine formulation of beclomethasone dipropionate with nonextrafine beclomethasone dipropionate and fluticasone pMDIs. The findings of the latter studies support the notion that both ICS alone or in combination with a LABA in an extrafine formulation can 
result in real-life improvements in lung function and disease control, independent of disease severity or smoking status. ${ }^{160}$

Vos and colleagues ${ }^{161}$ used functional imaging methods to study the effect of extrafine beclomethasone dipropionate/formoterol in steroid-naïve, partially and well-controlled subjects with asthma. The investigators reported significant improvements in airway resistance and asthma control scores, along with traditional lung function parameters and $\mathrm{F}_{\mathrm{ENO}}$ levels. Well-controlled subjects experienced an improvement in small airway volume even though traditional lung function parameters did not change significantly. ${ }^{161}$

The effects of bronchodilators on the SBN2 test have been extensively investigated in normal subjects and in subjects with asthma and COPD, but with contrasting results. No effects were observed in normal lungs, ${ }^{162-167}$ whereas in subjects with asthma, adrenergic agents have been shown to not only lower the slope of phase III but also to reduce the closing volume by increasing the vital capacity. ${ }^{168-173}$ Scichilone and colleagues ${ }^{174}$ compared the effects of extrafine beclomethasone dipropionate/formoterol on the SBN2 test and on bronchial hyper-reactivity with the effects on nonextrafine salmeterol/fluticasone in 30 subjects with asthma. The investigators reported that only beclomethasone dipropionate/formoterol achieved a significant improvement in the cumulative methacholine provocation dose and a trend toward a reduction in closing capacity. ${ }^{174}$ Farah and colleagues ${ }^{175}$ noted that the antiIL-5 monoclonal antibody mepolizumab was able to improve lung ventilation heterogeneity indexes in subjects with severe asthma after 26 weeks of treatment. Compared with placebo, omalizumab, a monoclonal antibody targeting serum immunoglobulin $\mathrm{E}$, failed to demonstrate a significant reduction in alveolar NO in subjects with moderate to severe asthma. ${ }^{176}$

Several trials are investigating the effect of other biologics approved for the treatment of severe asthma. A 12-week trial of the effects of benralizumab, a subcutaneous IL-5 receptor antagonist, on plethysmographic parameters and NO has recently been completed (NCT02869438). A mechanistic study (NCT03733535) will also investigate the effect of benralizumab on small airways by means of the forced oscillation technique, and ventilation heterogeneity will be assessed with the multiple-breath nitrogen washout and inhaled hyperpolarized ${ }^{129} \mathrm{Xe}$ MRI. A randomized controlled trial has been designed to assess the effects of benralizumab on air trapping and regional volume heterogeneity by means of quantitative CT scan indexes (NCT03976310). Changes in bronchial wall structure and airway inflammatory patterns induced by treatment with mepolizumab (NCT03797404) and benralizumab (NCT03953300) in subjects with severe asthma will be investigated in 2 ongoing trials.
Oral pharmacologic treatments have shown contrasting effects on small airways function in patients with asthma. The oral methylxanthine theophylline has long been used for chronic asthma treatment. ${ }^{177}$ However, the literature to support its effects on small airways in subjects with asthma is lacking. Conversely, the antileukotriene montelukast has been reported to reduce air-trapping indexes and closing volume and to improve regional lung ventilation in patients with moderate to severe asthma, either alone or when associated with salmeterol/fluticasone. ${ }^{178,179}$ Additionally, 24 weeks of treatment with montelukast reduced alveolar inflammation estimated with peripheral exhaled NO and reactance at low frequencies compared with placebo in subjects with stable asthma with background ICS treatment. ${ }^{180}$ In subjects with mild asthma, adding montelukast to fluticasone $250 \mu \mathrm{g}$ for 3 weeks reduced $\mathrm{F}_{\mathrm{ENO}}$ by $60 \%$ compared to baseline $\left(P<.001, P=.08\right.$ for alveolar NO) ${ }^{181}$

\section{Pharmacologic Targeting of Small Airways in COPD}

Small airways represent a major site of interest in patients with COPD. In fact, the peripheral lung constitutes the initial site of airway damage and a challenging diagnostic and pharmacologic target due to its peculiar anatomy and physiology, as well as the current limited ability to identify early disease. A body of literature supports the idea that available bronchodilators can improve the pathophysiological parameters that reflect small airway damage. Indeed, simple spirometry has a limited sensitivity both in detecting small airway disease and in assessing the modifications induced by inhaled therapy., $3,70,86,182$

R5-R20 and X5 measured with impulse oscillometry in subjects with COPD have been associated with worse airway obstruction, hyperinflation, and worse symptom burden. In fact, the degree of volume response in terms of FVC has been associated with the impairment of peripheral airway resistance. ${ }^{182}$ To date, anticholinergics and $\mathrm{B}_{2}$-agonists have exhibited comparable effects on several lung function parameters in patients with COPD. In acute conditions, patients with moderate to severe air-flow obstruction experience a similar reduction in inspiratory capacity, RV, and specific $R_{A W}$ when randomly exposed to tiotropium bromide or indacaterol. ${ }^{70}$ Moreover, post-bronchodilator changes in specific $\mathrm{R}_{\mathrm{AW}}$ were more closely related to bronchodilator-induced improvements of lung mechanics and dyspnea, making the reduction of specific $\mathrm{R}_{\mathrm{AW}}$ a better criterion to study the acute functional effect of bronchodilators than the traditional criteria based on $\mathrm{FEV}_{1}$ and $\mathrm{FVC}^{70}$

Small airway disease is not only associated with increases in static volumes and specific $\mathrm{R}_{\mathrm{AW}}$, but also with regional ventilation heterogeneity, which can be assessed with the SBN2 test or the multiple-breath nitrogen washout test. Indexes of ventilation heterogeneity are correlated with exercise capacity, exercise-induced desaturation, and 
dyspnea. ${ }^{183-188}$ The acute administration of tiotropium and indacaterol produced similar improvements in phase III slope, reduced the extent of airway closure, and increased $\mathrm{P}_{\mathrm{aO}_{2}}$ levels in subjects with moderate and severe COPD. ${ }^{86}$ Similar results were reported for aclidinium bromide and glycopyrronium. ${ }^{3}$

Compared with nonextrafine formulations, the intrapulmonary deposition of extrafine particles studied with the gamma scintigraphy technique, multi-slice CT scans, and computational fluid dynamics in subjects with moderate and severe COPD exhibited better regional lung deposition as well as significant improvements in static lung volumes and a reduction in extrathoracic drug deposition. ${ }^{147,150,189}$ This observation supports other results indicating that exposure to lower doses of ICS with the administration of an extrafine formulation of beclomethasone dipropionate yielded comparable results in preventing exacerbations and better odds of treatment stability at 2 y compared with nonextrafine fluticasone in subjects with moderate to very severe air-flow obstruction. ${ }^{190}$ In subjects with COPD, the administration of extrafine beclomethasone dipropionate/formoterol significantly improved FVC, ${ }^{191}$ air trapping, ${ }^{192,193}$ dyspnea ${ }^{193}$ and quality of life. ${ }^{194}$

More recently, the extrafine triple combination therapy of beclomethasone, formoterol and glycopyrronium have been studied in three large randomized clinical trials - that is, TRILOGY,${ }^{195}$ TRINITY, ${ }^{196}$ and TRIBUTE. ${ }^{197}$ In all trials, when coarse particles formulations were compared with the extrafine triple-combination therapy, the latter showed a statistically significant reduction in moderate and severe exacerbation risk. ${ }^{198}$

Some studies have investigated the effect of theophylline on small airway function in subjects with COPD. In COPD subjects with nonreversible air-flow obstruction, the administration of theophylline improved air trapping and airway resistance, with results comparable to those for salbutamol. ${ }^{199,200}$

\section{Clinical Implications and Future Developments}

The role of small airways in COPD and asthma has suffered from a paradox in the last century. In the 1950s and 1960s, we witnessed the rapid development of tests able to assess small airway disease, thus enabling the early detection of peripheral lung dysfunction in patients at risk for chronic respiratory disease. This rapid evolution was slowed by the poor reliability and repeatability of some of these tests, which were due mainly to the limited technologization of such procedures. At that time, the idea that smoking habit was to be abandoned due to its undeniable negative effects on health and society, may have led to the progressive loss of interest in small airway dysfunction in COPD, but also conditioned research. The subsequent development of new molecules and delivery systems made the research on small airways appealing again. Radiomorphological findings from the COPD-gene and CANCOLD research projects ${ }^{84,85}$ have added the imaging piece to the work conducted first by Weibel ${ }^{9}$ and later by researchers Harvard University and McGill University. Landmark papers that were recently published have allowed us to link morpho-functional data to the natural history of COPD and to highlight the importance of early pharmacologic intervention. Moreover, recent studies conducted on pathophysiological parameters such as closing volume and ventilation heterogeneity by means of the SBN2 test and new interpretations of body plethysmography should help integrate these biomarkers of small airway dysfunction into the monitoring process of the pharmacologic response to therapy and the follow-up of patients with both asthma and COPD.

Finally, the standardization of exhaled biomarkers such as NO has added an important tool to the everyday clinical practice of respiratory physicians involved in the management of patients with asthma. In patients with COPD, in addition to a classic inflammatory pathway, this evidence has modeled the idea of a new role of small airways in the natural history of chronic obstructive diseases. The mechanical stress produced by the small airway damage in emphysema may mechanically influence surrounding areas of normal lung, thus increasing the risk of lung function decline. ${ }^{84,86,201}$ However, no large clinical trial has yet reported the effectiveness of COPD treatments in slowing disease progression. The potential role of treatments able to reach the lung periphery and increase lung deposition may become a valid option in patients with small airway involvement in asthma and with early signs of COPD. In asthma, the concept of "future risk" has gained a paramount importance in the management of the disease, as emphasized by recent guidelines (https://ginasthma.org, accessed May 24, 2019). Whether the detection of small airway abnormalities will identify patients at major risk of asthma exacerbations or more severe disease, or identifies those likely to benefit from a specific intervention, is unknown and should be pursued in randomized clinical trials. ${ }^{2}$

\section{Summary}

Asthma and COPD are both characterized by small airway involvement and dysfunction. In most cases, the abnormalities of the peripheral lung can grow to a disproportionate degree before the damage is identified and treated, thus limiting the effects of the pharmacologic intervention. Reliable and simple tests are now available, and are consistent both in terms of sensitivity and repeatability for the identification of small airway disease, making the so-called silent zone much more noisy. Although advanced and intriguing, data on the structure 


\section{Small Airways in Obstructive Disease}

and function of small airways require clinical standardization and confirmatory results. Indeed, more effort should be devoted to the global functional assessment of patients at risk and patients with mild disease to achieve the goal of changing the natural history of asthma and COPD.

\section{REFERENCES}

1. Contoli M, Santus P, Papi A. Small airway disease in asthma: pathophysiological and diagnostic considerations. Curr Opin Pulm Med 2015;21(1):68-73.

2. Scichilone N, Contoli M, Paleari D, Pirina P, Rossi A, Sanguinetti $\mathrm{CM}$, et al. Assessing and accessing the small airways; implications for asthma management. Pulm Pharmacol Ther 2013;26(2):172-179.

3. Santus P, Radovanovic D, Di Marco F, Raccanelli R, Valenti V, Centanni S. Faster reduction in hyperinflation and improvement in lung ventilation inhomogeneity promoted by aclidinium compared to glycopyrronium in severe stable COPD patients. A randomized crossover study. Pulm Pharmacol Ther 2015;35:42-49.

4. Scichilone N, Benfante A, Morandi L, Bellini F, Papi A. Impact of extrafine formulations of inhaled corticosteroids/long-acting beta-2 agonist combinations on patient-related outcomes in asthma and COPD. Patient Relat Outcome Meas 2014;5:153-162.

5. Mead J. The lung's "quiet zone. N Engl J Med 1970;282(23):13181319.

6. Hogg JC, Macklem PT, Thurlbeck WM. Site and nature of airway obstruction in chronic obstructive lung disease. N Engl J Med 1968;278(25):1355-1360.

7. Lavorini F, Pedersen S, Usmani OS, Aerosol Drug Management Improvement Team (ADMIT). Dilemmas, confusion, and misconceptions related to small airways directed therapy. Chest 2017;151 (6):1345-1355.

8. Rohrer F. Der stromungswiderstand in der menschlichen atemwegen und der einfluss der unregelmassigen verzweigung es bronchial-systems auf der atmungsverlauf in vershiedenen lungenbezinken. Arch Ges Physiol 1915;162:225-229.

9. Weibel ER. Morphometry of the Human Lung. New York: Academic; 1963.

10. Green M. How big are the bronchioles? St. Thomas Hospital Gazette 1965:136-139.

11. Hogg JC, Paré PD, Hackett TL. The contribution of small airway obstruction to the pathogenesis of chronic obstructive pulmonary disease. Physiol Rev 2017;97(2):529-552.

12. Weibel ER, Sapoval B, Filoche M. Design of peripheral airways for efficient gas exchange. Respir Physiol Neurobiol 2005;148(1-2): 3-21.

13. Macklem PT, Mead J. Resistance of central and peripheral airways measured by a retrograde catheter. J Appl Physiol 1967;22(3):395401.

14. Van Brabandt H, Cauberghs M, Verbeken E, Moerman P, Lauweryns JM, Van de Woestijne KP. Partitioning of pulmonary impedance in excised human and canine lungs. J Appl Physiol Respir Environ Exerc Physiol 1983;55(6):1733-1742.

15. Terry PB, Traystman RJ, Newball HH, Batra G, Menkes HA. Collateral ventilation in man. N Engl J Med 1978;298(1):10-15.

16. Hogg W, Brunton J, Kryger M, Brown R, Macklem PT. Gas diffusion across collateral channels. J Appl Physiol 1972;33(5):568-575.

17. Niewoehner DE, Kleinerman J, Rice DB. Pathologic changes in the peripheral airways of young cigarette smokers. N Engl J Med 1974;291(15):755-758

18. Milic-Emili J, Torchio R, D’Angelo E. Closing volume: a reappraisal (1967-2007). Eur J Appl Physiol 2007;99(6):567-583.
19. Macklem PT. The physiology of small airways. Am J Respir Crit Care Med 1998;157(5 Pt 2):S181-S183.

20. Woolcock AJ, Vincent NJ, Macklem PT. Frequency dependence of compliance as a test for obstruction in the small airways. J Clin Invest 1969;48(6): 1097-1106.

21. Anthonisen NR, Bass H, Oriol A, Place RE, Bates DV. Regional lung function in patients with chronic bronchitis. Clin Sci 1968;35 (3):495-511.

22. Dollfuss RE, Milic-Emili J, Bates DV. Regional ventilation of the lung studied with boluses of 133 xenon. Respir Physiol 1967;2(2): 234-246.

23. Barnes PJ. Cellular and molecular mechanisms of asthma and COPD. Clin Sci (Lond) 2017;131(13):1541-1558.

24. Salvi SS, Barnes PJ. Chronic obstructive pulmonary disease in nonsmokers. Lancet 2009;374(9691):733-743.

25. Ramírez-Venegas A, Torres-Duque CA, Guzmán-Bouilloud NE, González-García M, Sansores RH. Small airway disease in COPD associated to biomass exposure. Rev Invest Clin 2019;71(1):70-78.

26. Barnes PJ. Inflammatory mechanisms in chronic obstructive pulmonary disease. J Allergy Clin Immunol 2016;138(1):16-27.

27. Hogg JC, Chu F, Utokaparch S, Woods R, Elliott WM, Buzatu L, et al. The nature of small-airway obstruction in chronic obstructive pulmonary disease. N Engl J Med 2004;350(26):2645-2653.

28. Barnes PJ. Immunology of asthma and chronic obstructive pulmonary disease. Nat Rev Immunol 2008;8(3):183-192.

29. Renda T, Baraldo S, Pelaia G, Bazzan E, Turato G, Papi A, et al. Increased activation of p38 MAPK in COPD. Eur Respir J 2008;31 (1):62-69.

30. Stewart JI, Criner GJ. The small airways in chronic obstructive pulmonary disease: pathology and effects on disease progression and survival. Curr Opin Pulm Med 2013;19(2):109-115.

31. Battaglia S, Mauad T, van Schadewijk AM, Vignola AM, Rabe KF, Bellia V, et al. Differential distribution of inflammatory cells in large and small airways in smokers. J Clin Pathol 2007;60(8):907-911.

32. De Grove KC, Provoost S, Verhamme FM, Bracke KR, Joos GF, Maes T, Brusselle GG. Characterization and quantification of innate lymphoid cell subsets in human lung. PloS One 2016;11(1): e0145961.

33. Di Stefano A, Caramori G, Gnemmi I, Contoli M, Vicari C, Capelli A, et al. T helper type 17-related cytokine expression is increased in the bronchial mucosa of stable chronic obstructive pulmonary disease patients. Clin Exp Immunol 2009;157(2):316-324.

34. Fahy JV, Dickey BF. Airway mucus function and dysfunction. N Engl J Med 2010;363(23):2233-2247.

35. Byers DE, Alexander-Brett J, Patel AC, Agapov E, Dang-Vu G, Jin $\mathrm{X}$, et al. Long-term IL-33-producing epithelial progenitor cells in chronic obstructive lung disease. J Clin Invest 2013;123(9): 3967-3982.

36. Rahman I, Marwick J, Kirkham P. Redox modulation of chromatin remodeling: impact on histone acetylation and deacetylation, NFkappaB and pro-inflammatory gene expression. Biochem Pharmacol 2004;68(6):1255-1267.

37. McDonough JE, Yuan R, Suzuki M, Seyednejad N, Elliott WM, Sanchez PG, et al. Small-airway obstruction and emphysema in chronic obstructive pulmonary disease. N Engl J Med 2011;365(17): 1567-1575.

38. Contoli M, Baraldo S, Marku B, Casolari P, Marwick JA, Turato G, et al. Fixed airflow obstruction due to asthma or chronic obstructive pulmonary disease: 5-year follow-up. J Allergy Clin Immunol 2010; 125(4):830-837.

39. Scichilone N, Battaglia S, Olivieri D, Bellia V. The role of small airways in monitoring the response to asthma treatment: what is beyond FEV1? Allergy 2009;64(11):1563-1569. 


\section{Small Airways in Obstructive Disease}

40. Hamid Q, Song Y, Kotsimbos TC, Minshall E, Bai TR, Hegele RG, Hogg JC. Inflammation of small airways in asthma. J Allergy Clin Immunol 1997;100(1):44-51

41. Carroll N, Cooke C, James A. The distribution of eosinophils and lymphocytes in the large and small airways of asthmatics. Eur Respir J 1997;10(2):292-300.

42. Kraft M, Djukanovic R, Wilson S, Holgate ST, Martin RJ. Alveolar tissue inflammation in asthma. Am J Respir Crit Care Med 1996;154 (5): $1505-1510$

43. Tulic MK, Christodoulopoulos P, Hamid Q. Small airway inflammation in asthma. Respir Res 2001;2(6):333-339.

44. Kraft M. Part III: location of asthma inflammation and the distal airways: clinical implications. Curr Med Res Opin 2007;23(sup3):S21S27.

45. Roche WR. Inflammatory and structural changes in the small airways in bronchial asthma. Am J Respir Crit Care Med 1998;157(5 Pt 2): S191-S194.

46. Haley KJ, Sunday ME, Wiggs BR, Kozakewich HP, Reilly JJ, Mentzer SJ, et al. Inflammatory cell distribution within and along asthmatic airways. Am J Respir Crit Care Med 1998;158(2):565-572.

47. Minshall EM, Hogg JC, Hamid QA. Cytokine mRNA expression in asthma is not restricted to the large airways. J Allergy Clin Immunol 1998;101(3):386-390.

48. Bonini M, Usmani OS. The role of the small airways in the pathophysiology of asthma and chronic obstructive pulmonary disease. Ther Adv Respir Dis 2015;9(6):281-293.

49. Carroll NG, Mutavdzic S, James AL. Distribution and degranulation of airway mast cells in normal and asthmatic subjects. Eur Respir J 2002;19(5):879-885.

50. Berry M, Hargadon B, Morgan A, Shelley M, Richter J, Shaw D, et al. Alveolar nitric oxide in adult with asthma: evidence of distal lung inflammation in refractory asthma. Eur Respir J 2005;25(6): 986-991.

51. Benayoun L, Druilhe A, Dombret MC, Aubier M, Pretolani M. Airway structural alterations selectively associated with severe asthma. Am J Respir Crit Care Med 2003;167(10):1360-1368.

52. Wenzel S. Severe asthma in adults. Am J Respir Crit Care Med 2005;172(2):149-160.

53. Kraft M, Pak J, Martin RJ, Kaminsky D, Irvin CG. Distal lung dysfunction at night in nocturnal asthma. Am J Respir Crit Care Med 2001;163(7):1551-1556.

54. Kraft M, Martin RJ, Wilson S, Djukanovic R, Holgate ST. Lymphocyte and eosinophil influx into alveolar tissue in nocturnal asthma. Am J Respir Crit Care Med 1999;159(1):228-234

55. Irvin CG, Pak J, Martin RJ. Airway-parenchyma uncoupling in nocturnal asthma. Am J Respir Crit Care Med 2000;161(1):50-56.

56. Liang Z, Zhang Q, Thomas CM, Chana KK, Gibeon D, Barnes PJ, et al. Impaired macrophage phagocytosis of bacteria in severe asthma. Respir Res 2014;15(1):72.

57. Pellegrino R, Viegi G, Brusasco V, Crapo RO, Burgos F, Casaburi R, et al. Interpretative strategies for lung function tests. Eur Respir J 2005;26(5):948-968.

58. Sorkness RL, Bleecker ER, Busse WW, Calhoun WJ, Castro M, Chung KF, et al. Lung function in adults with stable but severe asthma: air trapping and incomplete reversal of obstruction with bronchodilation. J Appl Physiol (1985) 2008;104(2):394-403.

59. Lipworth B, Manoharan A, Anderson W. Unlocking the quiet zone: the small airway asthma phenotype. Lancet Respir Med 2014;2 (6):497-506.

60. Ruppel GL. What is the clinical value of lung volumes? Respir Care 2012;57(1):26-35.

61. Despas PJ, Leroux M, Macklem PT. Site of airway obstruction in asthma as determined by measuring maximal expiratory flow breathing air and a helium-oxygen mixture. J Clin Invest 1972;51 (12):3235-3243

62. D’Angelo E, Santus P, Civitillo MF, Centanni S, Pecchiari M. Expiratory flow-limitation and heliox breathing in resting and exercising COPD patients. Respir Physiol Neurobiol 2009;169(3):291-296.

63. Reuben AD, Harris AR. Heliox for asthma in the emergency department: a review of the literature. Emerg Med J 2004;21(2):131-135.

64. Antic R, Macklem PT. The influence of clinical factors on site of airway obstruction in asthma. Am Rev Respir Dis 1976;114(5):851859.

65. Sood N, Turcotte SE, Wasilewski NV, Fisher T, Wall T, Fisher JT, Lougheed MD. Small-airway obstruction, dynamic hyperinflation, and gas trapping despite normal airway sensitivity to methacholine in adults with chronic cough. J Appl Physiol (1985) 2019;126(2):294304.

66. Stănescu D, Sanna A, Veriter C, Robert A. Identification of smokers susceptible to development of chronic airflow limitation: a 13-year follow-up. Chest 1998;114(2):416-425.

67. Halbert RJ, Natoli JL, Gano A, Badamgarav E, Buist AS, Mannino DM. Global burden of COPD: systematic review and meta-analysis. Eur Respir J 2006;28(3):523-532.

68. Timmins SC, Diba C, Farrow CE, Schoeffel RE, Berend N, Salome CM, King GG. The relationship between airflow obstruction, emphysema extent, and small airways function in COPD. Chest 2012;142 (2):312-319.

69. Santus P, Radovanovic D, Henchi S, Di Marco F, Centanni S, D'Angelo E, Pecchiari M. Assessment of acute bronchodilator effects from specific airway resistance changes in stable COPD patients. Respir Physiol Neurobiol 2014;197:36-45.

70. Santus P, Pecchiari M, Carlucci P, Boveri B, Di Marco F, Castagna F, Centanni S. Bronchodilation test in COPD: effect of inspiratory manoeuvre preceding forced expiration. Eur Respir J 2003;21(1): 82-85.

71. Borrill ZL, Houghton CM, Woodcock AA, Vestbo J, Singh D. Measuring bronchodilation in COPD clinical trials. $\mathrm{Br} \mathrm{J}$ Clin Pharmacol 2005;59(4):379-384.

72. D’Angelo E, Pecchiari M, Baraggia P, Saetta M, Balestro E, MilicEmili J. Low-volume ventilation causes peripheral airway injury and increased airway resistance in normal rabbits. J Appl Physiol (1985) 2002;92(3):949-956

73. D'Angelo E, Pecchiari M, Saetta M, Balestro E, Milic-Emili J. Dependence of lung injury on inflation rate during low-volume ventilation in normal open-chest rabbits. J Appl Physiol (1985) 2004;97 (1):260-268

74. Robertson B. Surfactant replacement in neonatal and adult respiratory distress syndrome. Eur J Anaesthesiol 1984;1(4):335-343.

75. Pecchiari M, Radovanovic D, Santus P, D'Angelo E. Airway occlusion assessed by single breath $\mathrm{N} 2$ test and lung P-V curve in healthy subjects and COPD patients. Respir Physiol Neurobiol 2016;234: 60-68.

76. Galvin I, Drummond GB, Nirmalan M. Distribution of blood flow and ventilation in the lung: gravity is not the only factor. $\mathrm{Br} \mathrm{J}$ Anaesth 2007;98(4):420-428.

77. Buist AS. Current status of small airways disease. Chest 1984;86 (1):100-105.

78. Gennimata SA, Palamidas A, Karakontaki F, Kosmas E, Koutsoukou A, Loukides S, Koulouris NG. Pathophysiology of evolution of small airways disease to overt COPD. COPD 2010;7(4):269-275.

79. Glaister DH, Schroter RC, Sudlow MF, Milic-Emili J. Transpulmonary pressure gradient and ventilation distribution in excised lungs. Respir Physiol 1973;17(3):365-385.

80. Warner DO, Hyatt RE, Rehder K. Inhomogeneity during deflation of excised canine lungs. I. Alveolar pressures. J Appl Physiol (1985) 1988;65(4):1757-1765. 


\section{Small Airways in Obstructive Disease}

81. Ingram RH, O'Cain CF, Fridy WWJr. Simultaneous quasi-static lung pressure-volume curves and "closing volume" measurements. J Appl Physiol 1974;36(2):135-141.

82. Demedts M, Clément J, Stănescu DC, van de Woestijne KP. Inflection point on transpulmonary pressure-volume curves and closing volume. J Appl Physiol 1975;38(2):228-235.

83. Kitaoka H, Kawase I. A novel interpretation of closing volume based on single-breath nitrogen washout curve simulation. J Physiol Sci 2007;57(6):367-376 .

84. Bhatt SP, Bodduluri S, Hoffman EA, Newell JDJr, Sieren JC, Dransfield MT, Reinhardt JM, COPD Gene Investigators. Computed tomography measure of lung at risk and lung function decline in chronic obstructive pulmonary disease. Am J Respir Crit Care Med 2017;196(5):569-576.

85. Kirby M, Tanabe N, Tan WC, Zhou G, Obeidat M, Hague CJ, et al. Total airway count on computed tomography and the risk of chronic obstructive pulmonary disease progression. Findings from a population-based study. Am J Respir Crit Care Med 2018;197(1):56-65.

86. Pecchiari M, Santus P, Radovanovic D, D'Angelo E. Acute effects of long-acting bronchodilators on small airways detected in COPD patients by single-breath N2 test and lung P-V curve. J Appl Physiol (1985) 2017;123(5):1266-1275.

87. Dutrieue B, Vanholsbeeck F, Verbanck S, Paiva M. A human acinar structure for simulation of realistic alveolar plateau slopes. J Appl Physiol (1985) 2000;89(5):1859-1867.

88. Verbanck S, Schuermans D, Van Muylem A, Melot C, Noppen M, Vincken W, Paiva M. Conductive and acinar lung-zone contributions to ventilation inhomogeneity in COPD. Am J Respir Crit Care Med 1998;157(5 Pt 1):1573-1577.

89. Verbanck S, Schuermans D, Paiva M, Vincken W. The functional benefit of anti-inflammatory aerosols in the lung periphery. J Allergy Clin Immunol 2006;118(2):340-346

90. Verbanck S, Schuermans D, Van Muylem A, Paiva M, Noppen M, Vincken W. Ventilation distribution during histamine provocation. J Appl Physiol (1985) 1997;83(6):1907-1916.

91. Verbanck S, Thompson BR, Schuermans D, Kalsi H, Biddiscombe $\mathrm{M}$, Stuart-Andrews $\mathrm{C}$, et al. Ventilation heterogeneity in the acinar and conductive zones of the normal ageing lung. Thorax 2012;67 (9):789-795.

92. Dubois AB, Brody AW, Lewis DH, Burgess BFJr. Oscillation mechanics of lungs and chest in man. J Appl Physiol 1956;8(6):587594.

93. Marotta A, Klinnert MD, Price MR, Larsen GL, Liu AH. Impulse oscillometry provides an effective measure of lung dysfunction in 4year-old children at risk for persistent asthma. J Allergy Clin Immunol 2003;112(2):317-322.

94. Smith HJ, Reinhold P, Goldman MD. Forced oscillation technique and impulse oscillometry. In: Gosselink R, Stam H, editors. Lung function testing: European respiratory society monograph, vol 31. Sheffield, UK: European Respiratory Society; 2005.

95. Nève V, Edmé J-L, Devos P, Deschildre A, Thumerelle C, Santos C, et al. Spirometry in 3-5-year-old children with asthma. Pediatr Pulmonol 2006;41(8):735-743.

96. Takeda T, Oga T, Niimi A, Matsumoto H, Ito I, Yamaguchi M, et al. Relationship between small airway function and health status, dyspnea and disease control in asthma. Respiration 2010;80(2):120-126.

97. Winkler J, Hagert-Winkler A, Wirtz H, Hoheisel G. Modern impulse oscillometry in the spectrum of pulmonary function testing methods. Pneumologie 2009;63(8):461-469.

98. Oppenheimer BW, Goldring RM, Berger KI. Distal airway function assessed by oscillometry at varying respiratory rate: comparison with dynamic compliance. COPD 2009;6(3):162-170.

99. Postma DS, Brightling C, Baldi S, Van den Berge M, Fabbri LM, Gagnatelli A, et al. Exploring the relevance and extent of small airways dysfunction in asthma (ATLANTIS): baseline data from a prospective cohort study. Lancet Respir Med 2019;7(5):402-416.

100. Alanazi AM, Abdelhameed AS. A spectroscopic approach to investigate the molecular interactions between the newly approved irreversible ErbB blocker "afatinib" and bovine serum albumin. PLoS ONE 2016;11(1):e0146297.

101. Brindicci C, Ito K, Resta O, Pride NB, Barnes PJ, Kharitonov SA. Exhaled nitric oxide from lung periphery is increased in COPD. Eur Respir J 2005;26(1):52-59.

102. Shahbazi S, Arif AA, Portwood SG, Thompson ME. Risk factors of smoking among health care professionals. J Prim Care Community Health 2014;5(4):228-233.

103. Alcázar-Navarrete B, Ruiz Rodríguez $\mathrm{O}$, Conde Baena P, Romero Palacios PJ, Agusti A. Persistently elevated exhaled nitric oxide fraction is associated with increased risk of exacerbation in COPD. Eur Respir J 2018;51(1):1701457.

104. Santus P, Radovanovic D, Mascetti S, Pauletti A, Valenti V, Mantero $\mathrm{M}$, et al. Effects of bronchodilation on biomarkers of peripheral airway inflammation in COPD. Pharmacol Res 2018;133:160-169.

105. Gono H, Fujimoto K, Kawakami S, Kubo K. Evaluation of airway wall thickness and air trapping by HRCT in asymptomatic asthma. Eur Respir J 2003;22(6):965-971.

106. Laurent F, Latrabe V, Raherison C, Marthan R, Tunon-de-Lara JM. Functional significance of air trapping detected in moderate asthma. Eur Radiol 2000;10(9):1404-1410.

107. Newman KB, Lynch DA, Newman LS, Ellegood D, Newell JDJr. Quantitative computed tomography detects air trapping due to asthma. Chest 1994;106(1):105-109.

108. Beigelman-Aubry C, Capderou A, Grenier PA, Straus C, Becquemin MH, Similowski T, Zelter M. Mild intermittent asthma: CT assessment of bronchial cross-sectional area and lung attenuation at controlled lung volume. Radiology 2002;223(1):181-187.

109. Goldin JG, Tashkin DP, Kleerup EC, Greaser LE, Haywood UM, Sayre JW, et al. Comparative effects of hydrofluoroalkane and chlorofluorocarbon beclomethasone dipropionate inhalation on small airways: assessment with functional helical thin-section computed tomography. J Allergy Clin Immunol 1999;104(6):S258-S267.

110. Jain N, Covar RA, Gleason MC, Newell JDJr, Gelfand EW, Spahn JD. Quantitative computed tomography detects peripheral airway disease in asthmatic children. Pediatr Pulmonol 2005;40(3):211-218.

111. Busacker A, Newell JDJr, Keefe T, Hoffman EA, Granroth JC, Castro M, et al. A multivariate analysis of risk factors for the air-trapping asthmatic phenotype as measured by quantitative $\mathrm{CT}$ analysis. Chest 2009;135(1):48-56.

112. Tunon-de-Lara JM, Laurent F, Giraud V, Perez T, Aguilaniu B, Meziane $\mathrm{H}$, et al. Air trapping in mild and moderate asthma: effect of inhaled corticosteroids. J Allergy Clin Immunol 2007;119(3):583590 .

113. Montaudon M, Lederlin M, Reich S, Begueret H, Tunon-de-Lara JM, Marthan R, et al. Bronchial measurements in patients with asthma: comparison of quantitative thin-section $\mathrm{CT}$ findings with those in healthy subjects and correlation with pathologic findings. Radiology 2009;253(3):844-853.

114. Tanabe N, Oguma T, Sato S, Kubo T, Kozawa S, Shima H, et al. Quantitative measurement of airway dimensions using ultra-high resolution computed tomography. Respir Investig 2018;56(6):489-496.

115. Thien F. Measuring and imaging small airways dysfunction in asthma. Asia Pac Allergy 2013;3(4):224-230.

116. Samee S, Altes T, Powers P, de Lange EE, Knight-Scott J, Rakes G, et al. Imaging the lungs in asthmatic patients by using hyperpolarized helium-3 magnetic resonance: assessment of response to methacholine and exercise challenge. J Allergy Clin Immunol 2003;111(6): 1205-1211. 


\section{Small Airways in Obstructive Disease}

117. de Lange EE, Altes TA, Patrie JT, Battiston JJ, Juersivich AP, Mugler JP3rd, Platts-Mills TA. Changes in regional airflow obstruction over time in the lungs of patients with asthma: evaluation with 3He MR imaging. Radiology 2009;250(2):567-575.

118. de Lange EE, Altes TA, Patrie JT, Parmar J, Brookeman JR, Mugler JP3rd, Platts-Mills TA. The variability of regional airflow obstruction within the lungs of patients with asthma: assessment with hyperpolarized helium-3 magnetic resonance imaging. J Allergy Clin Immunol 2007;119(5):1072-1078.

119. Gonem S, Hardy S, Buhl N, Hartley R, Soares M, Kay R, et al. Characterization of acinar airspace involvement in asthmatic patients by using inert gas washout and hyperpolarized (3)helium magnetic resonance. J Allergy Clin Immunol 2016;137(2):417-425.

120. Koo HK, Vasilescu DM, Booth S, Hsieh A, Katsamenis OL, Fishbane N, et al. Small airways disease in mild and moderate chronic obstructive pulmonary disease: a cross-sectional study. Lancet Respir Med 2018;6(8):591-602.

121. Vasilescu DM, Martinez FJ, Marchetti N, Galbán CJ, Hatt C, Meldrum CA, et al. Non-invasive imaging biomarker identifies small airway damage in severe chronic obstructive pulmonary disease. Am J Respir Crit Care Med 2019;200(5):575-581.

122. Decramer M, Celli B, Kesten S, Lystig T, Mehra S, Tashkin DP, UPLIFT Investigators. Effect of tiotropium on outcomes in patients with moderate chronic obstructive pulmonary disease (UPLIFT): a prespecified subgroup analysis of a randomised controlled trial. Lancet 2009;374(9696):1171-1178.

123. Tashkin DP, Celli B, Kesten S, Lystig T, Mehra S, Decramer M. Long-term efficacy of tiotropium in relation to smoking status in the UPLIFT trial. Eur Respir J 2010;35(2):287-294.

124. Tanabe N, Vasilescu DM, Kirby M, Coxson HO, Verleden SE, Vanaudenaerde BM, et al. Analysis of airway pathology in COPD using a combination of computed tomography, micro-computed tomography and histology. Eur Respir J 2018;51(2):1701245.

125. Magnussen $\mathrm{H}$, Holz O. Monitoring airway inflammation in asthma by induced sputum. Eur Respir J 1999;13(1):5-7.

126. Jögi J, Ekberg M, Jonson B, Bozovic G, Bajc M. Ventilation/perfusion SPECT in chronic obstructive pulmonary disease: an evaluation by reference to symptoms, spirometric lung function and emphysema, as assessed with HRCT. Eur J Nucl Med Mol Imaging 2011;38 (7):1344-1352.

127. Bajc M, Chen Y, Wang J, Li XY, Shen WM, Wang CZ, et al. Identifying the heterogeneity of COPD by V/P SPECT: a new tool for improving the diagnosis of parenchymal defects and grading the severity of small airways disease. Int J Chron Obstruct Pulmon Dis 2017;12:1579-1587.

128. Norberg P, Persson HL, Carlsson GA, Bake B, Kentson M, Sandborg M, Gustafsson A. Quantitative lung SPECT applied on simulated early COPD and humans with advanced COPD. EJNMMI Res 2013; $3(1): 28$.

129. Norberg P, Persson HL, Schmekel B, Carlsson GA, Wahlin K, Sandborg M, Gustafsson A. Does quantitative lung SPECT detect lung abnormalities earlier than lung function tests? Results of a pilot study. EJNMMI Res 2014;4(1):39.

130. Gershman NH, Wong HH, Liu JT, Mahlmeister MJ, Fahy JV. Comparison of two methods of collecting induced sputum in asthmatic subjects. Eur Respir J 1996;9(12):2448-2453.

131. Richter K, Holz O, Jörres RA, Mücke M, Magnussen H. Sequentially induced sputum in patients with asthma or chronic obstructive pulmonary disease. Eur Respir J 1999;14(3):697-701.

132. Tsoumakidou M, Tzanakis N, Siafakas NM. Induced sputum in the investigation of airway inflammation of COPD. Respir Med 2003;97 (8):863-871.
133. Usmani OS. Small airways dysfunction in asthma: evaluation and management to improve asthma control. Allergy Asthma Immunol Res 2014;6(5):376-388.

134. Usmani OS. Small-airway disease in asthma: pharmacological considerations. Curr Opin Pulm Med 2015;21(1):55-67.

135. Usmani OS. Treating the small airways. Respiration 2012;84(6):441453.

136. Labiris NR, Dolovich MB. Pulmonary drug delivery. Part I: physiological factors affecting therapeutic effectiveness of aerosolized medications. Br J Clin Pharmacol 2003;56(6):588-599.

137. Usmani OS, Biddiscombe MF, Barnes PJ. Regional lung deposition and bronchodilator response as a function of beta2-agonist particle size. Am J Respir Crit Care Med 2005;172(12):1497-1504.

138. de Boer AH, Gjaltema D, Hagedoorn P, Frijlink HW. Can 'extrafine' dry powder aerosols improve lung deposition? Eur J Pharm Biopharm 2015;96:143-151.

139. Chrystyn H, Price D. Not all asthma inhalers are the same: factors to consider when prescribing an inhaler. Prim Care Respir J 2009;18 (4):243-249.

140. Corradi M, Chrystyn H, Cosio BG, Pirozynski M, Loukides S, Louis $\mathrm{R}$, et al. NEXThaler, an innovative dry powder inhaler delivering an extrafine fixed combination of beclometasone and formoterol to treat large and small airways in asthma. Expert Opin Drug Deliv 2014;11 (9):1497-1506.

141. Laube BL, Janssens HM, de Jongh FH, Devadason SG, Dhand R, Diot $\mathrm{P}$, et al. What the pulmonary specialist should know about the new inhalation therapies. Eur Respir J 2011;37(6):1308-1331.

142. Vanden Burgt JA, Busse WW, Martin RJ, Szefler SJ, Donnell D. Efficacy and safety overview of a new inhaled corticosteroid, QVAR (hydrofluoroalkane-beclomethasone extrafine inhalation aerosol), in asthma. J Allergy Clin Immunol 2000;106(6):1209-1226.

143. Thompson PJ, Davies RJ, Young WF, Grossman AB, Donnell D. Safety of hydrofluoroalkane-134a beclomethasone dipropionate extrafine aerosol. Respir Med 1998;92(Suppl A):33-39.

144. Singh D, Piccinno A, Borrill Z, Poli G, Acerbi D, Meuleners L, Woodcock A. Tolerability of high cumulative doses of the HFA modulite beclomethasone dipropionate/formoterol combination inhaler in asthmatic patients. Pulm Pharmacol Ther 2008;21(3):551-557.

145. Busse WW, Brazinsky S, Jacobson K, Stricker W, Schmitt K, Vanden Burgt J, et al. Efficacy response of inhaled beclomethasone dipropionate in asthma is proportional to dose and is improved by formulation with a new propellant. J Allergy Clin Immunol 1999;104 (6): $1215-1222$.

146. Leach C, Colice GL, Luskin A. Particle size of inhaled corticosteroids: does it matter? J Allergy Clin Immunol 2009;124(Suppl 6): S88-S93.

147. De Backer J, Vos W, Vinchurkar S, Van Holsbeke C, Poli G, Claes $\mathrm{R}$, et al. The effects of extrafine beclometasone/formoterol (BDP/F) on lung function, dyspnea, hyperinflation, and airway geometry in COPD patients: novel insight using functional respiratory imaging. $\mathrm{J}$ Aerosol Med Pulm Drug Deliv 2015;28(2):88-99.

148. de Backer W, Devolder A, Poli G, Acerbi D, Monno R, Herpich C, et al. Lung deposition of BDP/formoterol HFA pMDI in healthy volunteers, asthmatic, and COPD patients. J Aerosol Med Pulm Drug Deliv 2010;23(3):137-148

149. Contoli M, Kraft M, Hamid Q, Bousquet J, Rabe KF, Fabbri LM, Papi A. Do small airway abnormalities characterize asthma phenotypes? In search of proof. Clin Exp Allergy 2012;42(8):1150-1160.

150. Caramori G, Pandit A, Papi A. Is there a difference between chronic airway inflammation in chronic severe asthma and chronic obstructive pulmonary disease? Curr Opin Allergy Clin Immunol 2005;5 (1):77-83.

151. Dolhnikoff M, da Silva LF, de Araujo BB, Gomes HA, Fernezlian S, Mulder A, et al. The outer wall of small airways is a major site of 


\section{Small Airways in Obstructive Disease}

remodeling in fatal asthma. J Allergy Clin Immunol 2009;123 (5):1090-1097.

152. Rigamonti E, Kottakis I, Pelc M, Rzymowska Feschenko GI. Y. Comparison of a new extra-fine beclomethasone dipropionate HFA 134a-formulated pMDI with a standard BDP CFC pMDI in adults with moderate persistent asthma. Eur Respir J 2006;28(Suppl 50): 1236.

153. Papi A, Paggiaro PL, Nicolini G, Vignola AM, Fabbri LM, Inhaled Combination Asthma Treatment versus SYmbicort (ICAT SY) Study Group. Beclomethasone/formoterol versus budesonide/formoterol combination therapy in asthma. Eur Respir J 2007;29(4):682-689.

154. Papi A, Paggiaro P, Nicolini G, Vignola AM, Fabbri LM, ICAT SE study group. Beclomethasone/formoterol vs fluticasone/salmeterol inhaled combination in moderate to severe asthma. Allergy 2007;62 (10):1182-1188.

155. Allegra L, Cremonesi G, Girbino G, Ingrassia E, Marsico S, Nicolini G, Terzano C, PRISMA (PRospectIve Study on asthMA control) Study Group. Real-life prospective study on asthma control in Italy: cross-sectional phase results. Respir Med 2012;106(2):205-214.

156. Terzano C, Cremonesi G, Girbino G, Ingrassia E, Marsico S, Nicolini G, Allegra L, PRISMA (PRospectIve Study on asthMA control) Study Group. 1-year prospective real life monitoring of asthma control and quality of life in Italy. Respir Res 2012;13(1):112.

157. Marth K, Spinola M, Kisiel J, Woergetter C, Petrovic M, Pohl W. Treatment response according to small airway phenotypes: a real-life observational study. Ther Adv Respir Dis 2016;10(3):200-210.

158. Contoli M, Bellini F, Morandi L, Forini G, Bianchi S, Gnesini G, et al. Assessing small airway impairment in mild-to-moderate smoking asthmatic patients. Eur Respir J 2016;47(4):1264-1267.

159. Cox CA, Boudewijn IM, Vroegop SJ, Schokker S, Lexmond AJ, Frijlink HW, et al. Extrafine compared to non-extrafine particle inhaled corticosteroids in smokers and ex-smokers with asthma. Respir Med 2017;130:35-42.

160. Brusselle G, Peché R, Van den Brande P, Verhulst A, Hollanders W, Bruhwyler J. Real-life effectiveness of extrafine beclometasone dipropionate/formoterol in adults with persistent asthma according to smoking status. Respir Med 2012;106(6):811-819.

161. Vos W, De Backer J, Poli G, De Volder A, Ghys L, Van Holsbeke C, et al. Novel functional imaging of changes in small airways of patients treated with extrafine beclomethasone/formoterol. Respiration 2013; 86(5):393-401.

162. Brooks SM, Barber MO. Changes in closing volume measurement after isoproterenol inhalation. Am Rev Respir Dis 1974;109(2):198204.

163. Collins JV, Clark TJ, Brown DJ. Airway function in healthy subjects and patients with left heart disease. Clin Sci Mol Med 1975;49(3): 217-228.

164. Collins JV, Clark TJ, McHardy-Young S, Cochrane GM, Crawley J. Closing volume in healthy non-smokers. Br J Dis Chest 1973;67 (1):19-27.

165. Hensley MJ, O'Cain CF, McFadden ER, Ingram RHJr. Distribution of bronchodilatation in normal subjects: beta agonist versus atropine. J Appl Physiol Respir Environ Exerc Physiol 1978;45(5):778-782.

166. Hoffstein V, Duguid N, McClean P, Zamel N. Nitrogen and bolus closing volumes: the effect of beta-agonist bronchodilator aerosol. Bull Eur Physiopathol Respir 1987;23(1):5-8.

167. Popa VT, Werner P. Dose-related dilatation of airways after inhalation of metaproterenol sulfate. Chest 1976;70(2):205-211.

168. Andersen LH, Haghfelt T. Regional lung function in asthmatics in remission before and after fenoterol. Bull Eur Physiopathol Respir 1980;16(2):215-288.

169. Riley DJ, Liu RT, Edelman NH. Enhanced responses to aerosolized bronchodilator therapy in asthma using respiratory maneuvers. Chest 1979;76(5):501-507.
170. Corda L, Gardenghi GG, Modina D, Montemurro LT, Novali M, Tantucci C. Effects on small airway obstruction of long-term treatments with beclomethasone/formoterol hydrofluoroalkane (metereddose inhaler) versus fluticasone/salmeterol (dry-powder inhaler) in asthma: a preliminary study. Allergy Asthma Proc 2011;32(6):29-34.

171. McCarthy D, Milic-Emili J. Closing volume in asymptomatic asthma. Am Rev Respir Dis 1973;107(4):559-570.

172. Sackner MA, Silva G, Zucker C, Marks MB. Long-term effects of metaproterenol in asthmatic children. Am Rev Respir Dis 1977;115 (6):945-953

173. Siegler D, Fukuchi Y, Engel L. Influence of bronchomotor tone on ventilation distribution and airway closure in asymptomatic asthma. Am Rev Respir Dis 1976;114(1):123-130.

174. Scichilone N, Battaglia S, Sorino C, Paglino G, Martino L, Paternò $\mathrm{A}$, et al. Effects of extra-fine inhaled beclomethasone/formoterol on both large and small airways in asthma. Allergy 2010;65(7):897-902.

175. Farah CS, Badal T, Reed N, Rogers PG, King GG, Thamrin C, et al. Mepolizumab improves small airway function in severe eosinophilic asthma. Respir Med 2019;148:49-53.

176. Pasha MA, Jourd'heuil D, Jourd'heuil F, Mahon L, Romero F, Feustel PJ, et al. The effect of omalizumab on small airway inflammation as measured by exhaled nitric oxide in moderate-to-severe asthmatic patients. Allergy Asthma Proc 2014;35(3):241-249.

177. Barnes PJ. Theophylline. Am J Respir Crit Care Med 2013;188 (8): $901-906$

178. Zeidler MR, Kleerup EC, Goldin JG, Kim HJ, Truong DA, Simmons $\mathrm{MD}$, et al. Montelukast improves regional air-trapping due to small airways obstruction in asthma. Eur Respir J 2006;27(2):307-315.

179. Gao JM, Cai F, Peng M, Ma Y, Wang B. Montelukast improves air trapping, not airway remodeling, in patients with moderate-to-severe asthma: a pilot study. Chin Med J (Engl) 2013;126(12):2229-2234.

180. Nakaji H, Petrova G, Matsumoto H, Iwata T, Ito I, Oguma T, et al. Effects of 24-week add-on treatment with ciclesonide and montelukast on small airways inflammation in asthma. Ann Allergy Asthma Immunol 2013;110(3):198-203.

181. Fritscher LG, Rodrigues MT, Zamel N, Chapman KR. The effect of montelukast on exhaled nitric oxide of alveolar and bronchial origin in inhaled corticosteroid-treated asthma. Respir Med 2009;103(2): 296-300.

182. Pisi R, Aiello M, Zanini A, Tzani P, Paleari D, Marangio E, et al Small airway dysfunction and flow and volume bronchodilator responsiveness in patients with chronic obstructive pulmonary disease. Int J Chron Obstruct Pulmon Dis 2015;10:1191-1197.

183. Boeck L, Gensmer A, Nyilas S, Stieltjes B, Re TJ, Tamm M, et al. Single-breath washout tests to assess small airway disease in COPD. Chest 2016;150(5):1091-1100.

184. Lopes AJ, Mafort TT. Correlations between small airway function, ventilation distribution, and functional exercise capacity in COPD patients. Lung 2014;192(5):653-659.

185. Santus P, Radovanovic D, Balzano G, Pecchiari M, Raccanelli R, Sarno N, et al. Improvements in lung diffusion capacity following pulmonary rehabilitation in COPD with and without ventilation inhomogeneity. Respiration 2016;92(5):295-307.

186. Di Marco F, Sotgiu G, Santus P, O’Donnell DE, Beeh K-M, Dore $\mathrm{S}$, et al. Long-acting bronchodilators improve exercise capacity in COPD patients: a systematic review and meta-analysis. Respir Res 2018;19(1):18.

187. Watz H, Mailänder C, Baier M, Kirsten A. Effects of indacaterol/glycopyrronium (QVA149) on lung hyperinflation and physical activity in patients with moderate to severe COPD: a randomised, placebocontrolled, crossover study (the MOVE study). BMC Pulm Med 2016;16(1):95.

188. Maltais F, O’Donnell D, Gáldiz Iturri JB, Kirsten A-M, Singh D, Hamilton A, et al. Effect of 12 weeks of once-daily tiotropium/ 


\section{Small Airways in Obstructive Disease}

olodaterol on exercise endurance during constant work-rate cycling and endurance shuttle walking in chronic obstructive pulmonary disease. Ther Adv Respir Dis 2018;12:1753465818755091.

189. Virchow JC, Poli G, Herpich C, Kietzig C, Ehlich H, Braeutigam D, et al. Lung deposition of the dry powder fixed combination beclometasone dipropionate plus formoterol fumarate using NEXThaler device in healthy subjects, asthmatic patients, and COPD patients. J Aerosol Med Pulm Drug Deliv 2018;31(5):269-280.

190. Postma DS, Roche N, Colice G, Israel E, Martin RJ, van Aalderen WM, et al. Comparing the effectiveness of small-particle versus large-particle inhaled corticosteroid in COPD. Int J Chron Obstruct Pulmon Dis 2014;9:1163-1186.

191. Singh D, Nicolini G, Bindi E, Corradi M, Guastalla D, Kampschulte $\mathrm{J}$, et al. FUTURE (Foster Upgrades TherapeUtic care in REspiratory disease) study group. Extrafine beclomethasone/formoterol compared to fluticasone/salmeterol combination therapy in COPD. BMC Pulm Med 2014;14:43.

192. Calverley PM, Kuna P, Monsó E, Costantini M, Petruzzelli S, Sergio $\mathrm{F}$, et al. Beclomethasone/formoterol in the management of COPD: a randomised controlled trial. Respir Med 2010;104(12):1858-1868.

193. Singh D, Kampschulte J, Wedzicha JA, Jones PW, Cohuet G, Corradi M, et al. A trial of beclomethasone/formoterol in COPD using EXACT-PRO to measure exacerbations. Eur Respir J 2013; 41(1):12-17.

194. Tzani P, Crisafulli E, Nicolini G, Aiello M, Chetta A, Clini EM, Olivieri D. Effects of beclomethasone/formoterol fixed combination on lung hyperinflation and dyspnea in COPD patients. Int J Chron Obstruct Pulmon Dis 2011;6:503-509.
195. Singh D, Papi A, Corradi M, Pavlišová I, Montagna I, Francisco C, et al. Single inhaler triple therapy versus inhaled corticosteroid plus long acting beta-agonist therapy for chronic obstructive pulmonary disease (TRILOGY): a double-blind, parallel group, randomized controlled trial. Lancet 2016;388(10048):963-973.

196. Vestbo J, Papi A, Corradi M, Blazhko V, Montagna I, Francisco C, et al. Single inhaler extrafine triple therapy versus long-acting muscarinic antagonist therapy for chronic obstructive pulmonary disease (TRINITY): a double-blind, parallel group, randomised controlled trial. Lancet 2017;389(10082):1919-1929.

197. Papi A, Vestbo J, Fabbri L, Corradi M, Prunier H, Cohuet G, et al. Extrafine inhaled triple therapy versus dual bronchodilator therapy in chronic obstructive pulmonary disease (TRIBUTE): a double-blind, parallel group, randomised controlled trial. Lancet 2018;391(10125): 1076-1084.

198. Mantero M, Radovanovic D, Santus P, Blasi F. Management of severe COPD exacerbations: focus on beclomethasone dipropionate/ formoterol/glycopyrronium bromide. Int J Chron Obstruct Pulmon Dis 2018;13:2319-2333.

199. Thomas P, Pugsley JA, Stewart JH. Theophylline and salbutamol improve pulmonary function in patients with irreversible chronic obstructive pulmonary disease. Chest 1992;101(1):160-165.

200. Umut S, Gemicioğlu B, Yildirim N, Barlas A, Ozüner Z. Effect of theophylline in chronic obstructive lung disease. Int $\mathrm{J}$ Clin Pharmacol Ther Toxicol 1992;30(5):149-152.

201. Santus P, Pecchiari M, Tursi F, Valenti V, Saad M, Radovanovic D. The airways' mechanical stress in lung disease: implications for COPD pathophysiology and treatment evaluation. Can Respir J 2019;2019:3546056 